\title{
Use of Smart Loads for Power Quality Improvement
}

\author{
Shuo Yan, Member, IEEE, Siew-Chong Tan, Senior Member, IEEE, Chi-Kwan Lee, Senior Member, IEEE, \\ Balarko Chaudhuri, Senior Member, IEEE, and S. Y. Ron Hui, Fellow, IEEE
}

\begin{abstract}
Electric spring (ES) was originally proposed as a distributed demand-side management technology for making noncritical loads adaptive to the availability of intermittent renewable power generation. The second generation of ES, fed with batteries (ES-2) and associated with a noncritical load, can form a new kind of combined smart load and distributed energy storage technology for smart grids. With its four-quadrant operation, ES-2 is able to offer ancillary grid services in addition to its major functions of voltage and frequency regulation. This paper presents the operating principles and the input current control of ES-2 for power quality improvement such as power factor correction and harmonics reduction. The operating principles and the proposed input current control have been verified with the experimental results obtained from a smallscale power grid. Another weak single-phase power system fed by intermittent wind power is set up to prove the combined operation of ES-2 for power quality improvement and ES-1 (ES with capacitor storage) for voltage stabilization. The experimental results show that ES-2 with input current control can carry out power quality improvement as its ancillary function.
\end{abstract}

Index Terms-Electric Springs (ESs), input current control, power quality, smart grids, smart loads.
At present, various methods for demand-side management have been proposed. They can be classified into time-based strategies and incentive-based strategies [7]. In general, the demand-side technologies require the participation of end users in making the decision of whether to respond to requests broadcasted by grid operators [8]. One obvious drawback is that the demand response with human-in-loop cannot enact automatically and is thus insufficient in resisting unpredictable contingencies [9]. The energy storage system located at the demand side can smooth the demand profile and react fast to transient events, but it remains an expensive solution [10].

Based on power electronics technology, the electric spring (ES) offers a fast solution in addressing power quality issues on the demand side. It possesses a few distinctive features, including the abilities to: 1) conduct direct reactive power compensation in maintaining a stable mains voltage; 2) offer indirect active power control in allowing the demand to follow the availability of renewable generation in a continuous and instantaneous fashion; and 3) operate without critical communication infrastructure. The association of an ES with a noncritical load (such as an electric water heater) essentially turn the load into a smart load that consumes energy adaptively. In typical commercial and residential buildings, about $45 \%$ of loads can be considered as noncritical [11].

The ES-1 presented in [12] uses reactive power of the power inverter and modulates the active power of the noncritical load to stabilize the mains voltage. Its second version (ES-2) proposed in [13] has more diverse functions. By adding battery storage across the dc link, ES-2 possesses eight operating modes and can provide both active and reactive power compensations. ES-2 with its associated battery storage also forms a new kind of combined smart loads and distributed energy storage technology. Based on ES-2, the three-phase ES was first introduced in [14]. It was implemented to reduce the power imbalance in a three-phase four-wire power system and also retains the useful function of ES-1 for voltage stabilization. Since the first paper in ES appeared in 2012 [12], active research on this topic has been conducted in the U.K. [15]-[17], Denmark [18], [19], China [20], Singapore [21], [22], Middle East [23], [24], and India [25], [26].

The original uses of distributed ES focus primarily on the instantaneous balance of power supply and demand with the aims of mitigating voltage and frequency fluctuations caused by the injection of intermittent renewable energy into the power grid. This project explores new application potential of ES-2 in improving the power quality of the distribution (lowvoltage) power grids, whilst retaining their original functions.

Unlike traditional flexible AC transmission (FACT) devices that are installed in a centralized manner for improving

Digital Object Identifier 10.1109/JESTPE.2016.2637398 


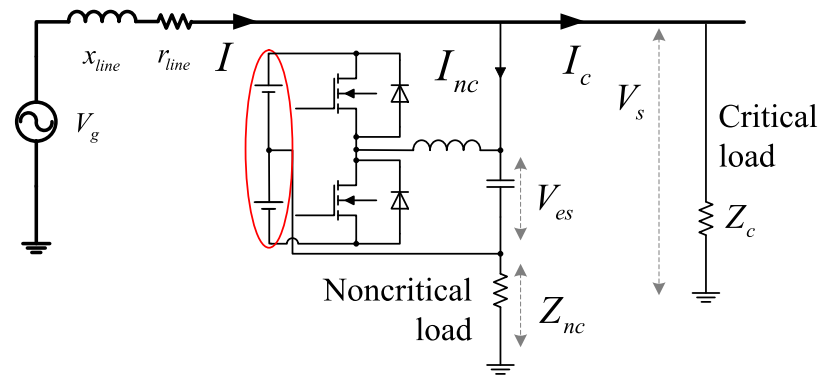

Fig. 1. Practical setup of ES-2.

power quality and controlling power flow in high-voltage and medium voltage transmission networks [27]-[30], ES is a distributed technology installed in the low-voltage distribution networks. The ES deals with the power quality issues on the demand side in a highly disturbed manner. Numerous ESs are expected to be distributed over the power grid in order to support system stability and provide power compensation (i.e., an analogy of using an array of mechanical springs to support a mattress). Thus, ES-2 can be perceived as a decentralized type of series power compensator that can voluntarily adapt the power of noncritical load in maintaining the supply-to-demand balance and possesses the power factor correction (PFC) features. This paper is an extension of a conference paper [31] and includes the full analysis and additional experimental results. These new results confirm that the integration of ESs and adaptive loads can perform PFC at both stable power grids and weak power grids.

\section{PRINCIPLES OF THE ES FOR PFC}

\section{A. Operating Modes of ES-2}

ES-2 is formed by adding a battery across the dc link of the original version (Fig. 1). Compared with ES-1 with capacitors, ES-2 can generate a voltage with any arbitrary phase angle, thereby allowing both active and reactive power to be exchanged. Compared with ES-1, ES-2 can provide six more operating modes in addition to inductive and capacitive mode.

The typical setup of the ES in a simple distribution grid is shown in Fig. 1. The operating mode of ES-2 is determined by the phasor relationship of $\boldsymbol{V}_{\mathrm{es}}$ and $\boldsymbol{I}_{\mathrm{nc}}$. For ES-1 with capacitors, $\boldsymbol{V}_{\mathrm{es}}$ can only be perpendicular to $\boldsymbol{I}_{\mathrm{nc}}$. However, for ES-2, $\boldsymbol{V}_{\mathrm{es}}$ can be in or out of phase with $\boldsymbol{I}_{\mathbf{n}}$ to give two more primary operating modes: 1) negative-resistive mode when an ES generates active power by discharging the batteries; and 2) resistive mode when an ES active power by charging the batteries. Thus, ES-2 possesses four primary operating modes. Building upon this, four other secondary operating modes, which are combinations of the four primary operating modes, are possible additions.

To simplify the discussion, the following assumptions are made. In the distribution power system given in Fig. 1, the mains voltage $\left(\boldsymbol{V}_{S}\right)$ is considered to be constant, and the noncritical load $\left(\boldsymbol{Z}_{\mathrm{nc}}\right)$ is resistive type. The operating mode of ES-2 can thus be determined by observing the vector positions of ES voltage $\left(\boldsymbol{V}_{\mathrm{es}}\right)$ and noncritical load voltage $\left(\boldsymbol{V}_{\mathbf{n c}}\right)$. From

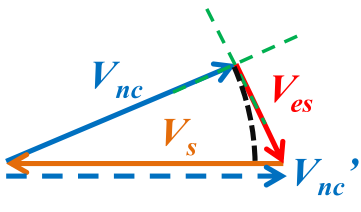

(a)

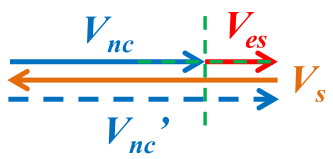

(c)

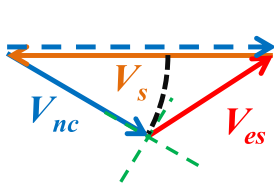

(e)

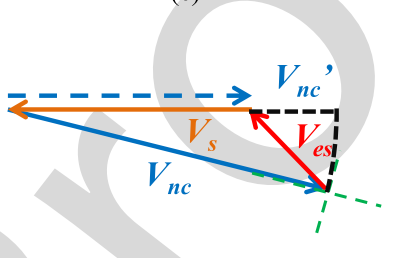

(g)

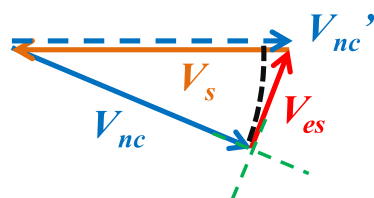

(b)

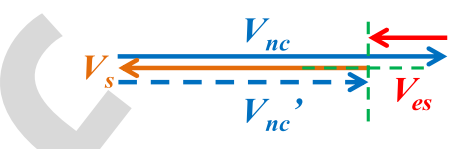

(d)

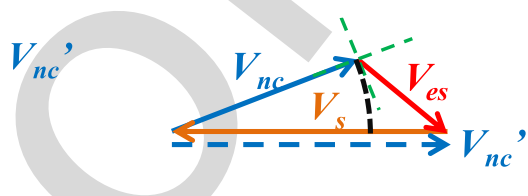

(f)

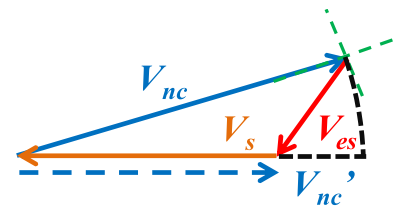

(h)
Fig. 2. Voltage vectors of the eight operating modes of ES-2. (a) Capacitive mode. (b) Inductive mode. (c) Resistive mode. (d) Negative resistive mode. (e) Inductive plus resistive mode. (f) Capacitive plus resistive mode. (g) Inductive plus negative resistive mode. (h) Capacitive plus negative resistive mode.

Fig. 2(a) and (b), pure capacitive and inductive modes can be accomplished by setting $\boldsymbol{V}_{\text {es }}$ to be perpendicular to $\boldsymbol{V}_{\text {nc }}\left(\boldsymbol{V}_{\text {es }}\right.$ is $90^{\circ}$ leading $\boldsymbol{V}_{\mathbf{n c}}$ for inductive mode and $90^{\circ}$ lagging $\boldsymbol{V}_{\mathbf{n c}}$ for capacitive mode). For these operating modes, ES-2 only exchanges reactive power with the power source. The original noncritical load voltage $\left(\boldsymbol{V}_{\mathbf{n c}}^{\prime}\right.$, the blue-dotted vector when ES-2 is absent), which is in opposite direction to the mains voltage $\left(\boldsymbol{V}_{s}\right)$, is relocated to a new position $\boldsymbol{V}_{\mathbf{n c}}$ (solid blue line) after the introduction of $\boldsymbol{V}_{\text {es }}$. As a result, $\boldsymbol{V}_{s}$ is decomposed into $\boldsymbol{V}_{\text {es }}$ and $\boldsymbol{V}_{\mathrm{nc}}$, which reduces the active power of noncritical loads. Thus, ES-2 in the inductive mode can reduce active power and increase reactive power, while ES-2 in the capacitive mode can reduce both active and reactive power. Fig. 2(c) and (d) show the voltage vectors of ES-2 working in resistive and negative-resistive modes. In both the cases, only active power is exchanged between ES-2 and the power source. The ES-2 in resistive mode introduces $\boldsymbol{V}_{\mathrm{es}}$, which suppresses $\boldsymbol{V}_{\mathbf{n c}}^{\prime}$ to $\boldsymbol{V}_{\mathbf{n c}}$ and thus reduces the active power of noncritical loads. In contrast, $\boldsymbol{V}_{\text {es }}$ of negative-resistive mode increases $\boldsymbol{V}_{\mathbf{n c}}^{\prime}$ to $\boldsymbol{V}_{\mathbf{n c}}$ and thus boosts the active power of noncritical loads.

Based on these four primary operating modes, four hybrid secondary operating modes would be possible, as shown in Fig. 2(e)-(h), in which active and reactive power are simultaneously exchanged between ES-2 and the power source. 


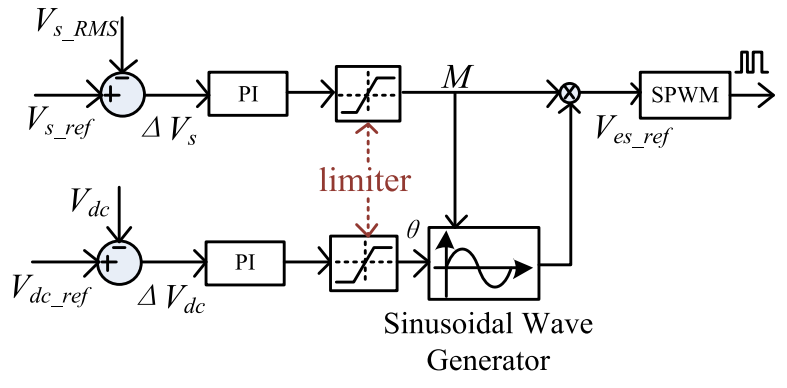

Fig. 3. Input voltage control of ES-1 [12].

Specifically, the four secondary modes are, namely, the resistive plus inductive mode, resistive plus capacitive mode, negative-resistive plus inductive mode, and negative-resistive plus capacitive mode. In all the eight operating modes, the introduction of the $\boldsymbol{V}_{\mathrm{es}}$ can change the loading of the system and thus change the state of the line current.

\section{B. Principle of ES-2 for PFC}

One particular application of ES-2 and its eight operating modes is PFC, which is used to minimize reactive power exchange by controlling the loading current to be in phase with the mains voltage. This technique is common in high-voltage transmissions with centralized compensation. In future smart grids, ES-2 can be installed in low-voltage distribution grid to perform the same task on the demand side.

The hardware implementation of ES-2 for PFC is shown in Fig. 1. The ES-2 here provides one regulated mains on its input and the other adaptive mains on its output. The noncritical load using the adaptive mains can help the utility companies to stabilize the power system and enhance the power quality. In the original ES implementation [12], the "input voltage control" is implemented to address the voltage fluctuation caused by intermittent renewable energy. The simplified control diagram is given in Fig. 3. Different from the ES-1 for voltage regulation, ES-2 is implemented with the "input current control" here to reduce the reactive power of the load bank.

In the setup shown in Fig. 1, the line current $(\boldsymbol{I})$ can be expressed as

$$
I=\frac{V_{s}-V_{\mathrm{es}}}{Z_{\mathrm{nc}}}+\frac{V_{s}}{Z_{c}}
$$

where $\boldsymbol{I}$ is the line current, $\boldsymbol{V}_{S}$ is the mains voltage, $\boldsymbol{V}_{\mathrm{es}}$ is the output voltage of ES-2, $\boldsymbol{Z}_{\mathrm{nc}}$ is the impedance of the noncritical load, and $\boldsymbol{Z}_{c}$ is the impedance of the critical load.

To further understand the relationship of $\boldsymbol{I}$ and $\boldsymbol{V}_{\mathrm{es}}$, the distribution line impedance $\left(\boldsymbol{Z}_{\text {line }}\right)$ is taken into account, which leads to

$V_{s}=\frac{V_{g}+\frac{Z_{\text {line }}}{Z_{\mathrm{nc}}} V_{\mathrm{es}}}{1+\frac{Z_{\text {line }}}{Z_{c}}+\frac{Z_{\text {line }}}{Z_{\mathrm{nc}}}}$

$192 \quad I=\frac{\frac{1}{Z_{c}}+\frac{1}{Z_{\mathrm{nc}}}}{1+\frac{Z_{\text {line }}}{Z_{c}}+\frac{Z_{\text {line }}}{Z_{\mathrm{nc}}}} V_{g}+\left(\frac{\left(\frac{1}{Z_{c}}+\frac{1}{Z_{\mathrm{nc}}}\right) \frac{Z_{\mathrm{line}}}{Z_{\mathrm{nc}}}}{1+\frac{Z_{\text {line }}}{Z_{c}}+\frac{Z_{\text {line }}}{Z_{\mathrm{nc}}}}-\frac{1}{Z_{\mathrm{nc}}}\right) V_{\mathrm{es}}$.
Equation (3) shows that in a power system with given $\boldsymbol{Z}_{\mathrm{nc}}$, $\boldsymbol{Z}_{c}$, and $\boldsymbol{Z}_{\text {line }}$, and a stable mains voltage $\boldsymbol{V}_{g}$ (or in a weak power grid with unstable mains voltage, the ES is implemented to maintain a stable mains voltage), the ES voltage $\boldsymbol{V}_{\text {es }}$ can be modulated to compensate for the line current $\boldsymbol{I}$.

To assist the control design, further mathematic analysis is conducted here. In a power system with fixed operating frequency (i.e., $f_{s}=50 \mathrm{~Hz}$ ), all the parameters in fundamental frequency can be expressed in the form of vectors and be located in one synchronous frame. When $\boldsymbol{V}_{g}$ is chosen as the reference vector $\left(\boldsymbol{V}_{g}=\left|V_{g}\right| \angle 0^{\circ}\right)$, these vectors can have constant amplitude and phase angle. By applying the notations given in (4) and (5), (3) is further transformed into (6) as

$$
\begin{aligned}
& \frac{\frac{1}{Z_{c}}+\frac{1}{Z_{\mathrm{nc}}}}{1+\frac{Z_{\text {line }}}{Z_{c}}+\frac{Z_{\text {line }}}{Z_{\mathrm{nc}}}}=b_{1}+b_{2} j \\
& \left(\frac{\left(\frac{1}{Z_{c}}+\frac{1}{Z_{\mathrm{nc}}}\right) \frac{Z_{\text {line }}}{Z_{\mathrm{nc}}}}{1+\frac{Z_{\text {line }}}{Z_{c}}+\frac{Z_{\text {line }}}{Z_{\mathrm{nc}}}}-\frac{1}{Z_{\mathrm{nc}}}\right)=b_{3}+b_{4} j \\
& \left\{\begin{array}{l}
I_{d_{-} 1 \mathrm{st}}=b_{1} V_{g}+b_{3} V_{\text {esd_1st }}-b_{4} V_{\text {esq_1st }} \\
I_{q_{-} 1 \mathrm{st}}=b_{2} V_{g}+b_{3} V_{\text {esq_1st }}+b_{4} V_{\text {esd_1st }} .
\end{array}\right.
\end{aligned}
$$

Equation (6) indicates that one single set of solution of fundamental active and reactive ES voltage ( $V_{\text {esd_1st }}$ and $\left.V_{\text {esq_1st }}\right)$ can be determined with the given fundamental active and reactive line currents (i.e., the references of fundamental active and reactive line current, $I_{d \_ \text {ref_1st }}$ and $I_{q}$ ref_1st $)$. In the control design, the fundamental active ES voltage $\left(V_{\text {esd_1st }}\right)$ is used to regulate the $d$ component of the fundamental line current $\left(I_{d_{-} 1 \mathrm{st}}\right)$, and the fundamental reactive ES voltage ( $\left.V_{\text {esq_1st }}\right)$ is left to compensate the $q$ component of the fundamental line current $\left(I_{q_{-} 1 \mathrm{st}}\right)$.

\section{Principle of ES-2 for PFC}

The usefulness of ES-2 in compensating the line current can be extended to reduce the harmonics generated by nonlinear load that commonly has a front-end converter for power modulation. Examples of nonlinear loads include power supplies for telecom systems, banking machines, and servers. Obviously, certain nonlinear loads such as banking machine require a stable power supply and thus can be considered as critical loads. The ES and its associated noncritical load can be used to remove the adverse effects caused by nonlinear loads. The principle of using the ES to remove the harmonics in line current can be mathematically expressed by rewriting (1) in sinusoidal form and extending it with the consideration of the harmonics. To simplify the analysis, noncritical load is considered as pure resistive load in (7), as shown at the bottom of the next page, in which $i$ denotes the order of harmonics, $\omega$ denotes the fundamental frequency, $\theta_{I} \theta_{V s} \theta_{\mathrm{Ves} \_i} \theta_{\mathrm{Ic} \_i}$ are, respectively the phase angle of line current, mains voltage, ES voltage, and critical load current.

To mitigate the harmonics, the second part on the righthand side of (7) must be equal to zero, so that $\boldsymbol{I}$ contains only a fundamental component. Thus, this requires ES-2 to generate corresponding voltage harmonics, which are of the same orders as the harmonics in $\boldsymbol{I}_{c}$. The remaining first part 
on the left-hand side of (7) represents the filtered line current at the fundamental frequency.

\section{Load-Dependent Characteristics}

The above assumption of noncritical load as pure resistive load is not a necessary condition in implementing an ES system [15]-[17]. Here, (1) is rewritten as (8) to evaluate the impact of noncritical loads on the operation of the ES

$$
I=\left(\frac{1}{Z_{\mathrm{nc}}}+\frac{1}{Z_{c}}\right) \cdot V_{s}-\frac{1}{Z_{\mathrm{nc}}} \cdot V_{\mathrm{es}}
$$

The second part on the right-hand side of (8) indicates the variable part of noncritical current ( $\Delta \boldsymbol{I}_{\mathrm{nc}}$ ) with respect to the ES voltage. In the synchronous frame established in Section II-B, the second part on the right-hand side of (8) can be rewritten as

$$
\left\{\begin{array}{l}
\Delta I_{\mathrm{nc} \_d}=\frac{1}{\left|Z_{\mathrm{nc}}\right|}\left(-\mathrm{PF} \cdot V_{\mathrm{es} \_d}-\sqrt{1-\mathrm{PF}^{2}} \cdot V_{\mathrm{es} \_q}\right) \\
\Delta I_{\mathrm{nc} \_q}=\frac{1}{\left|Z_{\mathrm{nc}}\right|}\left(\sqrt{1-\mathrm{PF}^{2}} \cdot V_{\mathrm{es} \_d}-\mathrm{PF} \cdot V_{\mathrm{es} \_q}\right)
\end{array}\right.
$$

if the power factor of the noncritical load is considered.

Equation (9) further gives

$$
\Delta I_{\mathrm{nc} \_d}^{2}+\Delta I_{\mathrm{nc} \_q}^{2}=\frac{V_{\mathrm{es}}^{2}}{\left|Z_{\mathrm{nc}}\right|^{2}}
$$

From (9) and (10), two general conclusions can be drawn on the impact of noncritical load on the operation of the ES system as follows.

1) The power factor of noncritical load has no impact on the dispatchable range of noncritical load current. The amplitudes of ES voltage and load impedance determine the boundary of this dispatchable range.

2) The power factor of the noncritical load determines the weighting of $V_{\text {es } \_d}$ and $V_{\text {es } \_q}$ on $\Delta I_{\text {nc } \_d}$ and $\Delta I_{\text {nc } \_q}$. For the case of pure resistive load, $\Delta I_{\mathrm{nc} \_} d$ and $\Delta I_{\mathrm{nc} \_q}$ are, respectively, dependent on $V_{\text {es_ } d}$ and $V_{\text {es_ } q}$.

\section{INPUT CURRENT CONTROL OF ES-2 FOR POWER QUALITY IMPROVEMENT}

\section{A. Structure of Input Current Controller}

Based on the above discussion, an input current controller should be used for ES-2 in regulating the line current. The complete input current control consists of two parts, one for reactive power compensation and the other for harmonics cancellation. These two parts can operate independently or collectively.

The first part for reactive power compensation is highlighted with the blue rectangle, as shown in Fig. 4. A fast Fourier transformation (FFT) is set up to derive the frequency

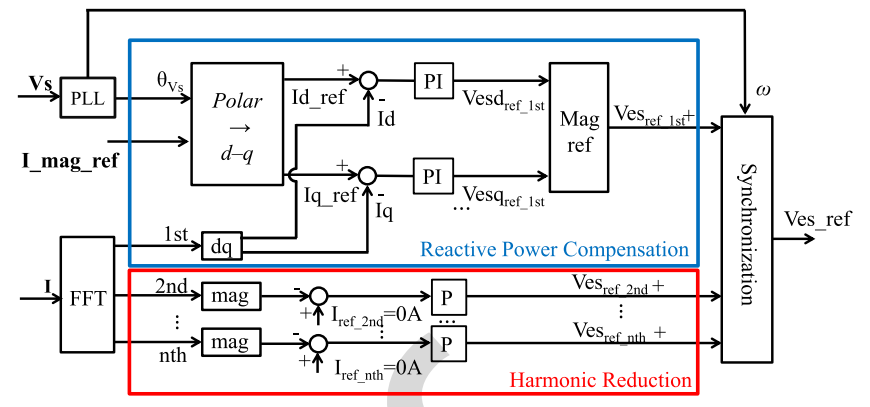

Fig. 4. Control diagram of ES for power quality improvement.

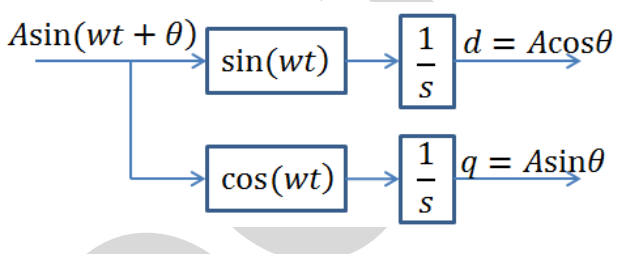

Fig. 5. $d-q$ transformation.

sequences of line current. The fundamental line current is fed back and decomposed into active $\left(I_{d_{-} 1 \mathrm{st}}\right)$ and reactive $\left(I_{q \_1 s t}\right)$ current. Equations (11) and (12) give the mathematical expressions of the "polar to $d-q$ " transformation, and Fig. 5 shows the corresponding block diagram

$$
\begin{aligned}
& d=A \cos \theta=\frac{2}{T} \int_{T_{n}}^{T_{n+1}} A \sin (\omega t+\theta) \sin (\omega t) d t \\
& q=A \sin \theta=\frac{2}{T} \int_{T_{n}}^{T_{n+1}} A \sin (\omega t+\theta) \cos (\omega t) d t .
\end{aligned}
$$

To minimize the reactive power consumption of the load bank, the reference of reactive line current $\left(I_{q_{-} \text {ref_lst }}\right)$ is set to be zero $\left(I_{q_{-} \text {ref_1st }}=0 \mathrm{~A}\right)$. The reference of active line current ( $\left.I_{d_{-} \text {ref_1st }}\right)$ is set to keep the total active power unchanged. $I_{d_{-} 1 \mathrm{st}}$ and $I_{q_{-} 1 \mathrm{st}}$ are compared with their references $\left(I_{d_{-} \text {ref_1 } 1 \mathrm{st}}\right.$ and $\left.I_{q_{-} \text {ref_1st }}\right)$. Two PI controllers are set up to process the error of the respective active and reactive current in generating the fundamental active and reactive ES voltage reference $\left(V_{\text {esd_ref_1st }}\right.$ and $\left.V_{\text {esq_ref_1st }}\right)$. The mathematical expressions of the control are given as

$$
\begin{aligned}
& V_{\text {esd_ref_1st }}=\left(K_{p_{-} \mathrm{Id}}+K_{i_{-} \mathrm{Id}} / s\right) \cdot\left(I_{d_{-} \text {ref_1st }}-I_{d_{-} 1 \mathrm{st}}\right) \\
& V_{\text {esq_ref_1st }}=\left(K_{p_{-} \mathrm{Iq}}+K_{i_{-} \mathrm{Iq}} / s\right) \cdot\left(I_{q_{-} \text {ref_1st }}-I_{q_{-} 1 \mathrm{st}}\right) \text {. }
\end{aligned}
$$

The control loops inside the red box in Fig. 4 are the part of the input current control for harmonics mitigation. The harmonic currents in the second and higher orders acquired by the FFT block are sent to the controller. To remove the harmonics contained in line current, the amplitude of all the

$$
\begin{aligned}
\sum_{i=1}^{n} I_{i \mathrm{th}} \sin \left(i \omega t+\theta_{I_{\mathrm{ith}}}\right)= & \left(\frac{V_{s} \sin \left(\omega t+\theta_{V s}\right)-V_{\mathrm{es} \_1 \mathrm{st}} \sin \left(\omega t+\theta_{\mathrm{Ves} \_1 \mathrm{st}}\right)}{R_{\mathrm{nc}}}+I_{C_{-} 1 \mathrm{st}} \sin \left(\omega t+\theta_{\mathrm{Ic} \_1 \mathrm{st}}\right)\right) \\
& +\left(-\frac{1}{R_{\mathrm{nc}}} \sum_{i=2}^{n} V_{\mathrm{es} \_i \mathrm{th}} \sin \left(i \omega t+\theta_{\text {Ves } \_i \mathrm{th}}\right)+\sum_{i=2}^{n} I_{C_{-} i \mathrm{th}} \sin \left(i \omega t+\theta_{\mathrm{Ic} i \mathrm{th}}\right)\right)
\end{aligned}
$$




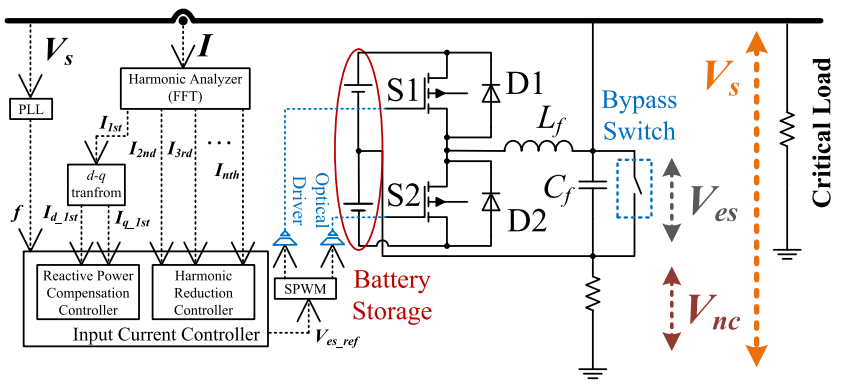

Fig. 6. Hardware implementation of an input current controller.

TABLE I

SPECIFICATIONS OF ES-2 HARDWARE

\begin{tabular}{ccc}
\hline \hline Descriptions & Parameters & Values \\
\hline Switching frequency & $f_{\text {switch }}$ & $20 \mathrm{kHz}$ \\
MOSFET switches & $S_{l}, S_{2}$ & IRFP30N50 \\
Filter inductor & $L_{f}$ & $L=500 \mu \mathrm{H}$ \\
Filter capacitor & $C_{f}$ & $C=13.2 \mu \mathrm{F}$ \\
Battery voltage & $V_{\text {battery }}$ & $2 \times 125 \mathrm{~V}, 5 \mathrm{AH} \mathrm{Lead-Acid}$ \\
Sampling frequency & $f_{s}$ & $10 \mathrm{kHz}$ \\
\hline \hline
\end{tabular}

harmonic current references in the second and higher orders are set to zero $\left(I_{\text {ref_2nd }}=0 \mathrm{~A}, I_{\text {ref_3rd }}=0 \mathrm{~A}, \ldots, I_{\text {ref } \_n \text {th }}=\right.$ 0 A). The phasor information of these harmonic currents is fed back to the synchronization stage. P controllers are implemented to process the errors of the amplitude of the harmonic currents in deriving the ES voltage references in the second and higher orders. The general control for the mitigation of current harmonics is mathematically presented as

$V_{\text {es_ref } \_i t h}=K_{p_{-} i t h} \cdot\left(I_{\text {ref } \_i t h}-I_{i \text { th }}\right), \quad i=2,3,4, \ldots, n$.

\section{B. Hardware Implementation of Input Current Controller}

A prototype of the ES-2 system with the implementation of the "input current control" is developed. The hardware structure is shown in Fig. 6. The power converter used for ES2 is a half-bridge inverter with batteries on dc link and with an $L C$ output filter. In the hardware setup, a relay is connected across the output capacitor to bypass ES. This arrangement can show the different conditions in the system before and after ES-2 is switched ON. Blocks including feedback processing block, phase lock loop for synchronization, $d-q$ transformation block for decoupling, and sinusoidal pulsewidth modulation for inverter control are also set up. The controller is implemented in dSpace 1104. The sampling frequency is set to be $10 \mathrm{kHz}$. The PWM pulse has a switching frequency of $20 \mathrm{kHz}$ and a deadband of $20 \mathrm{nS}$. The specifications of the hardware setup are given in Table I.

\section{EXPERIMENTAL RESUlts}

\section{A. ES-2 for Reactive Power Compensation in a Stiff Power} System

A low-voltage single-phase power system is set up as shown in Fig. 7. It consists of a constant ac power source, a short

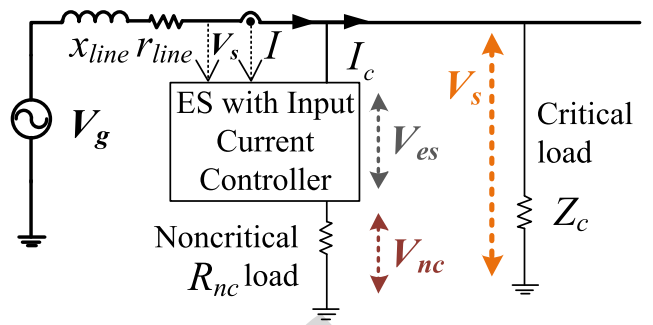

Fig. 7. Experimental setup.

TABLE II

SPECIFICATIONS OF EXPERIMENTAL SETUP

\begin{tabular}{ccc}
\hline \hline Descriptions & Parameters & Values \\
\hline Power source & $V_{g}$ & $110 \mathrm{~V}$ (RMS) \\
voltage & $Z_{\text {line }}$ & line $=0.2 \Omega, x_{\text {line }}=0.8 \Omega$ \\
Distribution line & $R_{n c 1}$ & $120 \Omega$ \\
impedance & $R_{n c 2}$ & $150 \Omega$ \\
Noncritical load 1 & $220+j 220 \Omega$ \\
Noncritical load 2 & $Z_{c 1}$ & (capacitive-resistive type) \\
Critical load 1 & $220-j 220 \Omega$ \\
Critical load 2 & $Z_{c 2}$ & (inductive-resistive type) \\
\hline \hline
\end{tabular}

distribution line, a resistive noncritical load, an ES-2, and a critical load. Specifications of the setup can be found in Table II. The ES-2 is programmed to perform reactive power compensation with the input current control. A capacitiveresistive and an inductive-resistive critical load with low PF are used, respectively, to examine the reactive power compensation capability of ES-2. In the middle of operations, the noncritical load is changed from 120 to $150 \Omega$ for evaluating the dynamic response of the ES system.

Measured waveforms of the operating states of the system with a capacitive-resistive critical load are recorded in Fig. 8(a). The enlarged waveforms of the two transient states when ES-2 is turned ON and the noncritical load is changed from 120 to $150 \Omega$ are also included. It can be observed that the ES can react fast enough to the change in noncritical load. Measured waveforms of the first steady states of the system when ES-2 is inactivated are shown in Fig. 8(b). The system has a PF of 0.94 (leading). Measurements of the second steady states of the system are shown in Fig. 8(c). ES-2 operates in inductive mode to compensate the phase angle of line current $(\boldsymbol{I})$ to $1^{\circ}$, and the PF of the system is corrected to 0.99 (leading). Measurements of the third steady states are recorded in Fig. 8(d) to show the operation of the ES system after the noncritical load is changed to $150 \Omega$. The PF remains compensated to 0.99 (leading), when ES-2 operates in inductive mode and generates a compensation voltage with a larger RMS value to match the new load condition.

The second experiment is conducted with an inductiveresistive critical load. ES-2 is turned ON to correct PF to be close to 1.0. Fig. 9(a) shows the measured waveforms of operating states of the ES-2 system and the enlarged waveforms of two transient states when ES-2 is turned ON and the noncritical load is changed from 120 to $150 \Omega$. In the first 
With ES

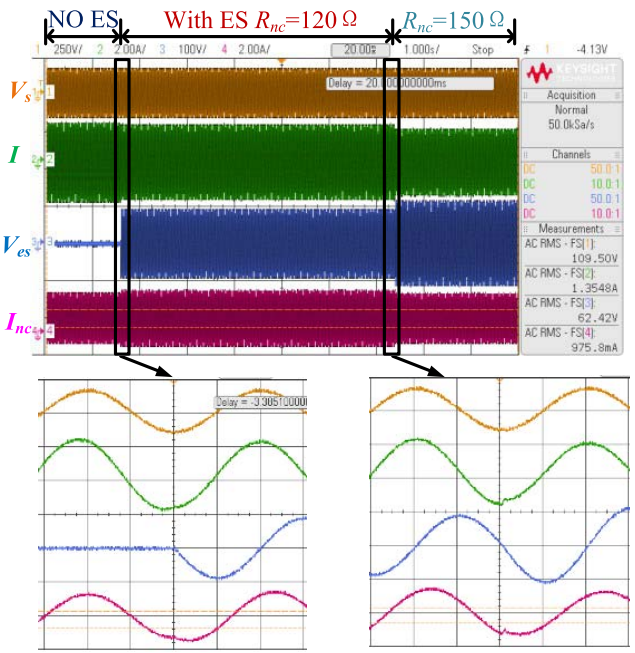

(a)

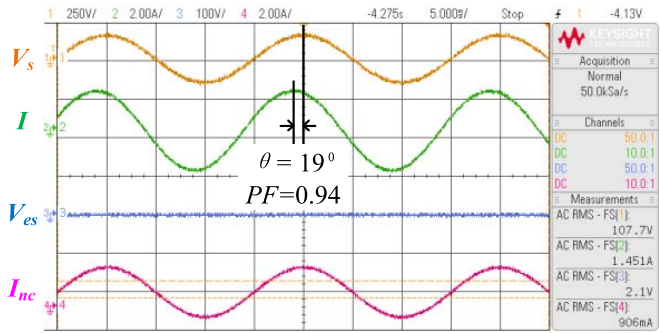

(b)

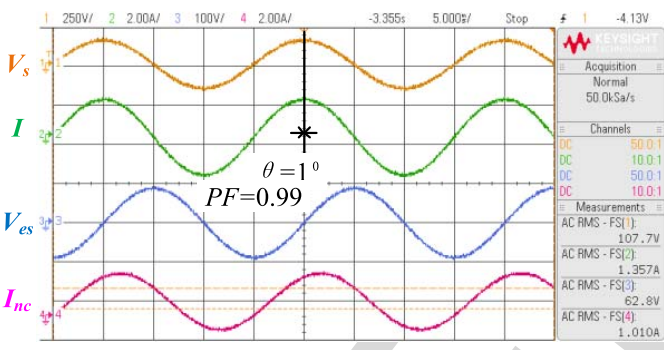

(c)

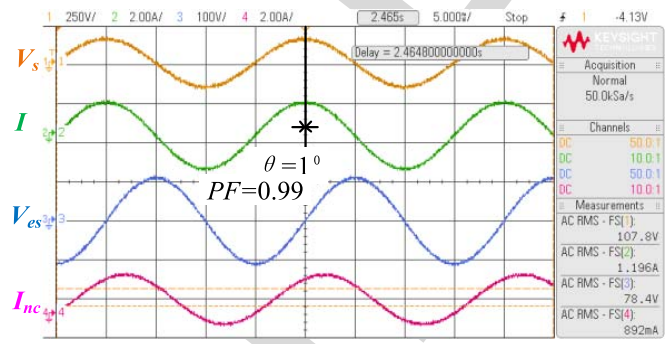

(d)

Fig. 8. (a) Captured waveforms of operating states and enlarged transient states for capacitive-resistive load. (b) Captured waveforms of the steady states without ES-2. (c) Captured waveforms of the steady states with ES-2 $\left(R_{\mathrm{nc} 1}=120 \Omega\right)$. (d) Captured waveforms of the steady states with ES-2 $\left(R_{\mathrm{nc} 2}=150 \Omega\right)$. steady states shown in Fig. 9(a), the system is uncompensated and has PF of 0.94 (lagging). In the second steady states shown in Fig. 9(b), ES-2 operates in capacitive mode to correct the PF of the system to 0.99 (lagging). Measurements of the third steady states of the system after the noncritical load are

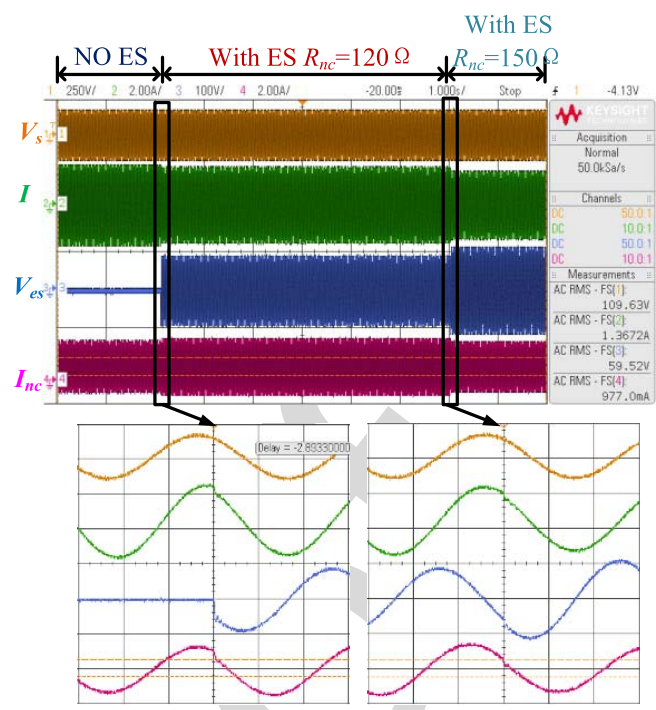

(a)

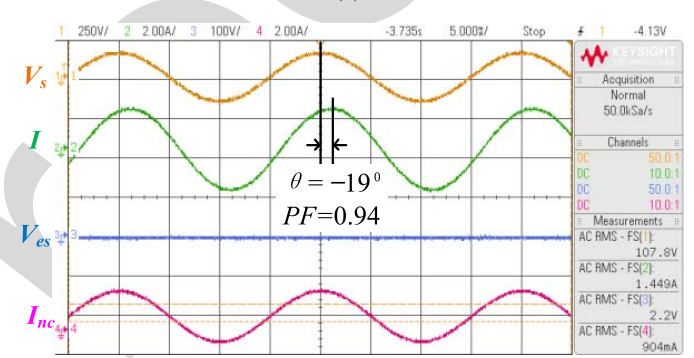

(b)

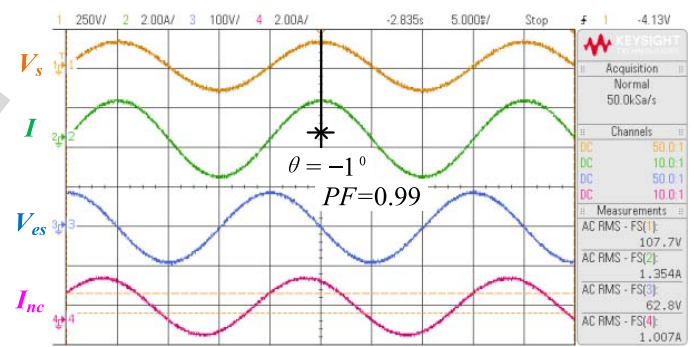

(c)

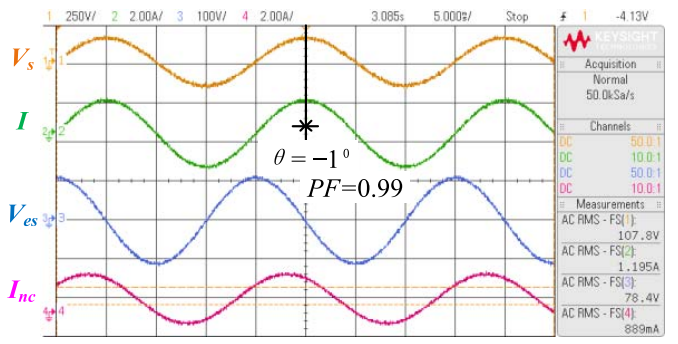

(d)

Fig. 9. (a) Captured waveforms of operating states and enlarged transient states for inductive-resistive load. (b) Captured waveforms of the steady states without ES-2. (c) Captured waveforms of the steady states with ES-2 $\left(R_{\mathrm{nc} 1}=120 \Omega\right)$. (d) Captured waveforms of the steady states with ES-2 $\left(R_{\mathrm{nc} 2}=150 \Omega\right)$.

changed to $150 \Omega$ are shown in Fig. 9(c). The PF of the system remains at 0.99 (lagging), when ES-2 operates in capacitive mode and generates a compensation voltage with a larger RMS value to match the new noncritical load condition. 


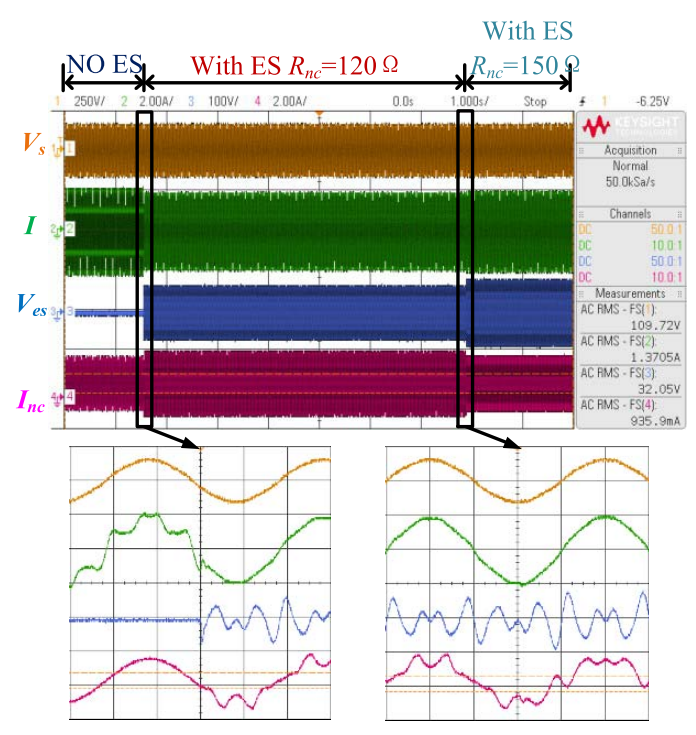

(a)

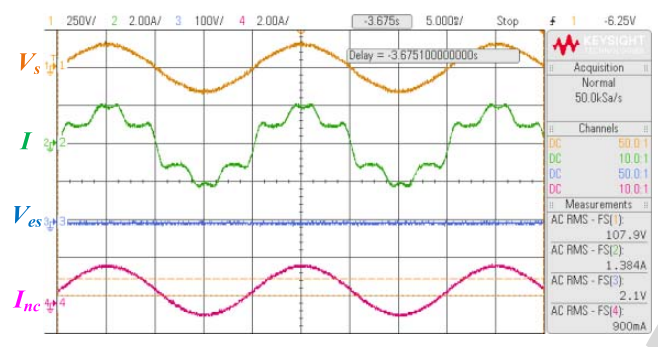

(b)

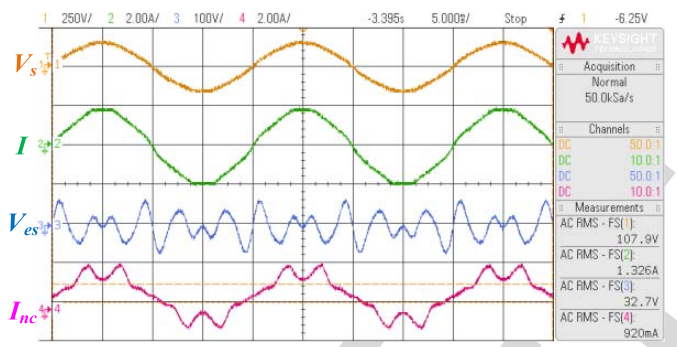

(c)

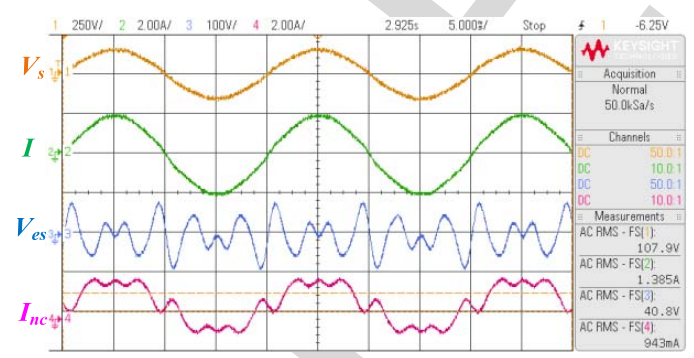

(d)

Fig. 10. (a) Captured waveforms of operating states and enlarged transient states for nonlinear load. (b) Captured waveforms of the steady states without ES-2. (c) Captured waveforms of the steady states with ES-2 $\left(R_{\mathrm{nc} 1}=120 \Omega\right)$. (d) Captured waveforms of the steady states with ES-2 $\left(R_{\mathrm{nc} 2}=150 \Omega\right)$.
TABLE III

SPECIFICATIONS OF POWER System With Two ESs

\begin{tabular}{ccc}
\hline \hline Descriptions & Parameters & Values \\
\hline Power source & $V_{g}$ & $230 \mathrm{~V}(\mathrm{RMS})$ \\
voltage & & \\
Distribution line & $Z_{\text {line }}$ & $r_{\text {line }}=0.2 \Omega, x_{\text {line }}=0.8 \Omega$ \\
impedance & $R_{n c 1}$ & $77 \Omega$ \\
Noncritical load 1 & $R_{n c 2}$ & $77 \Omega$ \\
Noncritical load 2 & $Z_{c}$ & $-j 116 \Omega$ (inductive) \\
Critical load &
\end{tabular}

Fig. 11. Experimental setup.

120 to $150 \Omega$ to test the dynamic response of the ES- 2 system. Measurements of the operating states of the system are shown in Fig. 10(a). The waveforms of the two transient states when the ES is activated and the noncritical load is changed are enlarged. It can be observed that the ES system reacts fast enough to cope with the sudden change in load condition. Fig. 10(b) shows the measurements of the first steady states of the system before ES-2 is turned ON. The line current $(\boldsymbol{I})$ is severely distorted due to the implementation of the nonlinear load. Measured waveforms of the second steady states of the system when the ES is activated are shown in Fig. 10(c). ES-2 generates the counteracting harmonic voltage to compensate the nonlinear load. The waveform of the line current $(\boldsymbol{I})$ is significantly improved. Measurements of the third steady states after the noncritical load is changed are shown in Fig. 10(d). The ES-2 generates a harmonic voltage with a larger RMS value to match the changed noncritical load condition.

\section{Combined Operation of ES-1 and ES-2}

In this experiment, a weak grid with unstable mains voltage is emulated with a programmable power source. A large critical inductive load is used to simulate a power grid with a low power factor. Two ESs (ES-1 and ES-2) associated with their respective noncritical loads are set up as shown in Fig. 11. Both noncritical loads are assumed to be of resistive type. ES-1 is used to reduce the mains voltage fluctuation. The control algorithm shown in Fig. 3 is adopted here [12]. ES-2 implemented with the input current control is used to improve the power factor. The specifications of the system are given in Table III.

The experimental results in Fig. 12 repeat the useful function of ES-1 to stabilize the mains voltage. Fig. 13 shows the power of critical load. It can be seen that the fluctuation of 


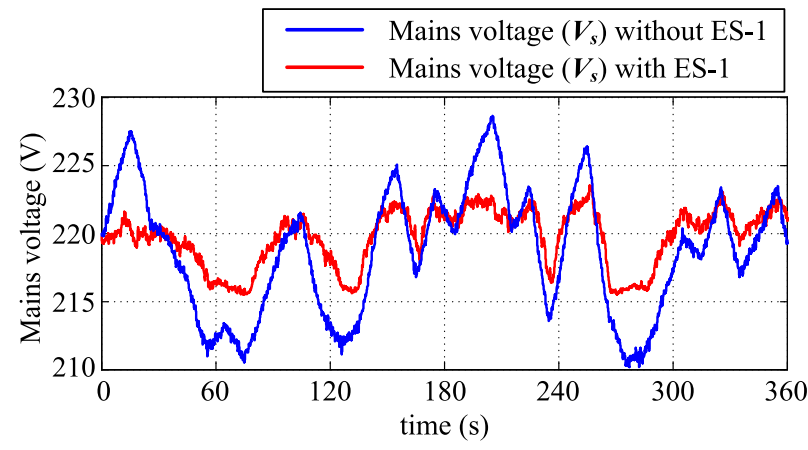

Fig. 12. Mains voltage with and without ES-1 for voltage stabilization.

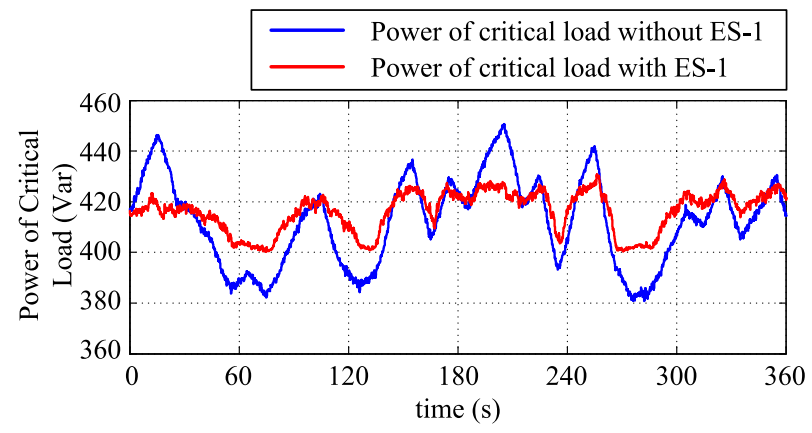

Fig. 13. Power consumption of critical load with and without ES-1.

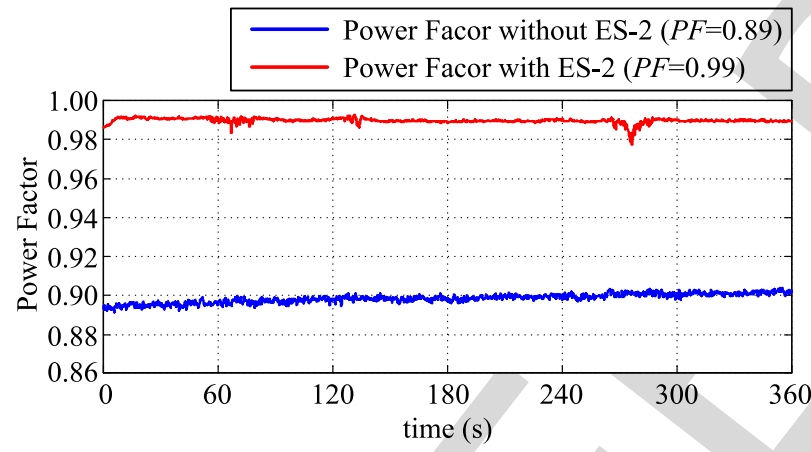

Fig. 14. Power factor with and without ES-2.

presented and practically verified. The joint operation of ES-1 in stabilizing the mains voltage and ES-2 in performing PFC has been experimentally confirmed in a single-phase hardware power system setup. The experimental results indicate the promising performance of the ES technology as a future distributed demand-side management and distributed energy storage solution.

\section{REFERENCES}

[1] H. Farhangi, "The path of the smart grid," IEEE Power Energy Mag., vol. 8, no. 1, pp. 18-28, Jan./Feb. 2010.

[2] V. C. Gungor et al., "Smart grid technologies: Communication technologies and standards," IEEE Trans. Ind. Informat., vol. 7, no. 4, pp. 529-539, Nov. 2011.

[3] A. Vargas and M. E. Samper, "Real-time monitoring and economic dispatch of smart distribution grids: High performance algorithms for DMS applications," IEEE Trans. Smart Grid, vol. 3, no. 2, pp. 866-877, Jun. 2012.

[4] F. Li et al., "Smart transmission grid: Vision and framework," IEEE Trans. Smart Grid, vol. 1, no. 2, pp. 168-177, Sep. 2010.

[5] D. E. Bakken, A. Bose, C. H. Hauser, D. E. Whitehead, and G. C. Zweigle, "Smart generation and transmission with coherent, realtime data," Proc. IEEE, vol. 99, no. 6, pp. 928-951, Jun. 2011.

[6] P. Palensky and D. Dietrich, "Demand side management: Demand response, intelligent energy systems, and smart loads," IEEE Trans. Ind Informat., vol. 7, no. 3, pp. 381-388, Aug. 2011.

[7] Federal Energy Regulatory Commission (FERC). (Dec. 2012). Assessment of Demand Response and Advanced Metering. [Online]. Available: http://www.ferc.gov/legal/staff-reports/12-20-12-demand-response.pdf

[8] J. S. Vardakas, N. Zorba, and C. V. Verikoukis, "A survey on demand response programs in smart grids: Pricing methods and optimization algorithms," IEEE Commun. Surveys Tut., vol. 17, no. 1, pp. 152-178, 1st Quart., 2015.

[9] T. Samad, E. Koch, and P. Stluka, "Automated demand response for smart buildings and microgrids: The state of the practice an research challenges," Proc. IEEE, vol. 104, no. 4, pp. 726-744, Apr. 2016.

[10] P. F. Ribeiro, B. K. Johnson, M. L. Crow, A. Arsoy, and Y. Liu, "Energy storage systems for advanced power applications," Proc. IEEE, vol. 89 no. 12, pp. 1744-1756, Dec. 2001

[11] Hong Kong Energy End-Use Data 2013, Electrical \& Mechanical Services Department, Hong Kong Government, 2013.

[12] S. Y. R. Hui, C. K. Lee, and F. F. Wu, "Electric springs-A new smart grid technology," IEEE Trans. Smart Grid, vol. 3, no. 3, pp. 1552-1561, Sep. 2012.

[13] S.-C. Tan, C. K. Lee, and S. Y. Hui, "General steady-state analysis and control principle of electric springs with active and reactive power compensations," IEEE Trans. Power Electron., vol. 28, no. 8, pp. 3958-3969, Aug. 2013.

[14] S. Yan, S.-C. Tan, C.-K. Lee, B. Chaudhuri, and S. Y. Hui, "Electric springs for reducing power imbalance in three-phase power systems," IEEE Trans. Power Electron., vol. 30, no. 7, pp. 3601-3609, Jul. 2015.

[15] Z. Akhtar, B. Chaudhuri, and S. Y. Hui, "Primary frequency control contribution from smart loads using reactive compensation," IEEE Trans. Smart Grid, vol. 6, no. 5, pp. 2356-2365, Sep. 2015.

[16] Z. Akhtar, B. Chaudhuri, and S. Y. Hui, "Smart loads for voltage contro in distribution networks," IEEE Trans. Smart Grid, (early access).

[17] D. Chakravorty, B. Chaudhuri, and S. Y. Hui, "Rapid frequency response from smart loads in great britain power system," IEEE Trans. Smart Grid, (early access)

[18] Q. Wang, M. Cheng, Z. Chen, and Z. Wang, "Steady-state analysis of electric springs with a novel $\delta$ control," IEEE Trans. Power Electron., vol. 30, no. 12, pp. 7159-7169, Dec. 2015.

[19] Q. Wang, M. Cheng, Z. Chen, and G. Buja, "A novel topology and its control of single-phase electric springs," in Proc. Int. Conf. Renew. Energy Res. Appl. (ICRERA), Nov. 2015, pp. 267-272.

[20] X. Che, T. Wei, Q. Huo, and D. Jia, "A general comparative analysis of static synchronous compensator and electric spring," in Proc. IEEE Conf. Expo Transp. Electrific. Asia-Pacific (ITEC Asia-Pacific), Aug./Sep. 2014, pp. 1-5.

[21] K. R. Krishnanand, S. M. F. Hasani, J. Soni, and S. K. Panda, "Neutral current mitigation using controlled electric springs connected to microgrids within built environment," in Proc. IEEE Energy Convers. Congr. Expo. (ECCE), Sep. 2014, pp. 2947-2951. 

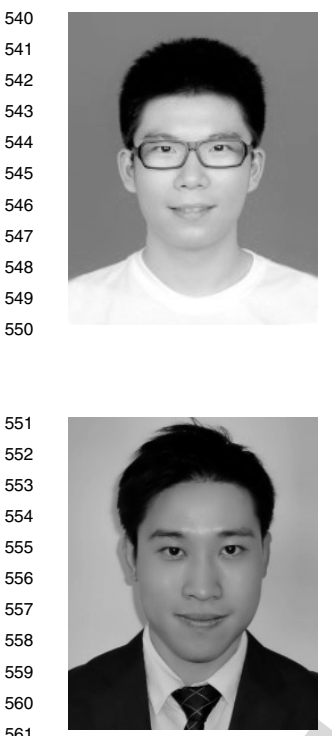

Shuo Yan (M'16) received the B.Eng. degree from the University of South China, Hengyang, China, in 2007, the M.Phil. degree from Southeast University, Nanjing, China, in 2010, and the Ph.D. degree from The University of Hong Kong, Hong Kong, in 2016. $\mathrm{He}$ is currently a Post-Doctoral Research Fellow with the Department of Electrical and Electronic Engineering, The University of Hong Kong. His current research interests include power electronic technology in smart grid, the advance control of renewable energy sources, and microgrid.

Siew-Chong Tan (M'06-SM'11) received the B.Eng. (Hons.) and M.Eng. degrees in electrical and computer engineering from the National University of Singapore, Singapore, in 2000 and 2002, respectively, and the Ph.D. degree in electronic and information engineering from The Hong Kong Polytechnic University, Hong Kong, in 2005.

From 2005 to 2012, he was a Research Associate, Post-Doctoral Fellow, Lecturer, and an Assistant Professor with the Department of Electronic and Information Engineering, The Hong Kong Polytechnic University. In 2009, he was a Visiting Scholar at the Grainger Center for Electric Machinery and Electromechanics, University of Illinois at UrbanaChampaign, Champaign, IL, USA. In 2011, he was a Senior Scientist with the Agency for Science, Technology and Research (A*Star), Singapore, and an Invited Academic Visitor of the Huazhong University of Science and Technology, Wuhan, China. He is currently an Associate Professor with the Department of Electrical and Electronic Engineering, The University of Hong Kong, Hong Kong. He has co-authored the book Sliding Mode Control of Switching Power Converters: Techniques and Implementation (Boca Raton, FL, USA: CRC, 2011). His current research interests include power electronics and control, LED lightings, smart grids, and clean energy technologies.

Dr. Tan serves extensively as a reviewer for various IEEE/IET transactions and journals on power, electronics, circuits, and control engineering. He is an Associate Editor of the IEEE TRANSACTIONS ON POWER ELECTRONICS.

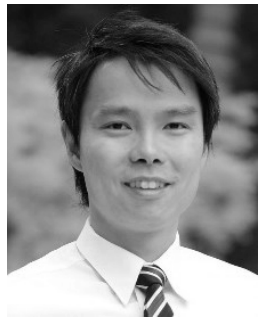

Chi-Kwan Lee (M'08-SM'14) received the B.Eng. and $\mathrm{Ph} . \mathrm{D}$. degrees in electronic engineering from the City University of Hong Kong, Hong Kong, in 1999 and 2004, respectively.

He was a Post-Doctoral Research Fellow with the Power and Energy Research Center, National University of Ireland, Galway, Ireland, from 2004 to 2005. In 2006, he joined the Center of Power Electronics, City University of Hong Kong, as a Research Fellow. He has been a Visiting Researcher with Imperial College London, London, U.K., since 2010. He was a Lecturer of Electrical Engineering with The Hong Kong Polytechnic University, Hong Kong, from 2008 to 2011. He is currently an Assistant Professor with the Department of Electrical and Electronic Engineering, The University of Hong Kong, Hong Kong. His current research interests include wireless power transfer, clean energy technologies, and smart grids.

Dr. Lee received the IEEE Power Electronics Transactions First Prize Pape Award for his publications on Mid-Range Wireless Power Transfer in 2015. $\mathrm{He}$ is a Co-Inventor of the Electric Springs and planar EMI filter.

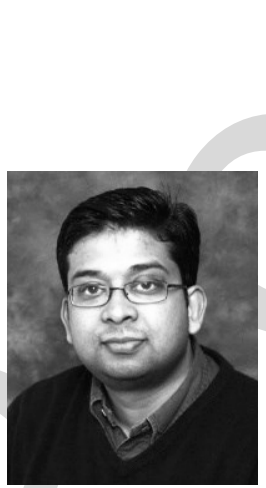

Balarko Chaudhuri (M'06-SM'11) received the $\mathrm{Ph} . \mathrm{D}$. degree in electrical and electronic engineering from Imperial College London, London, U.K., in 2005

$\mathrm{He}$ is currently a Senior Lecturer with the Control and Power Research Group, Imperial College London. His current research interests include power systems stability, grid integration of renewables, HVDC, FACTS, demand response, and smart grids.

Dr. Chaudhuri is a fellow of the Institution of Engineering and Technology and a member of the International Council on Large Electric Systems. He is an Editor of the IEEE TRANSACTIONS ON SMART GRID and an Associate Editor of the IEEE Systems Journal and Elsevier Control Engineering Practice.

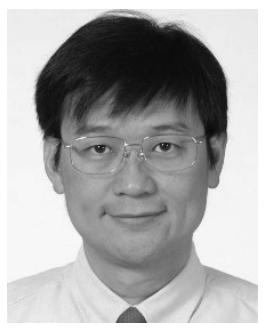

S. Y. Ron Hui (M'87-SM'94-F'03) received the B.Sc. degree (Eng.) (Hons.) from the University of Birmingham, Birmingham, U.K., in 1984, and the D.I.C. and Ph.D. degrees from Imperial College London, London, U.K. in 1987.

He currently holds the Philip Wong Wilson Wong Chair Professorship at The University of Hong Kong, Hong Kong, and a part-time Chair Professorship at Imperial College London. He has authored over 300 technical papers, including more than 220 refereed journal publications, and over 60 of his patents have been adopted by industry.

Dr. Hui received the IEEE Rudolf Chope Research and Development Award from the IEEE Industrial Electronics Society and the IET Achievement Medal (The Crompton Medal) in 2010, and the IEEE William E. Newell Power Electronics Award in 2015. He is an Associate Editor of the IEEE TRANS ACTIONS ON POWER ELECTRONICS and the IEEE TRANSACTIONS ON INDUSTRIAL ELECTRONICS, and an Editor of the IEEE JOURNAL OF EMERGING AND Selected Topics in Power Electronics. His inventions on wireless charging platform technology underpin key dimensions of Qi, the world's first wireless power standard, with freedom of positioning and localized charging features for wireless charging of consumer electronics.

Dr. Hui is a Fellow of the Australian Academy of Technology and Engineering and the Royal Academy of Engineering, U.K. 


\title{
Use of Smart Loads for Power Quality Improvement
}

\author{
Shuo Yan, Member, IEEE, Siew-Chong Tan, Senior Member, IEEE, Chi-Kwan Lee, Senior Member, IEEE, \\ Balarko Chaudhuri, Senior Member, IEEE, and S. Y. Ron Hui, Fellow, IEEE
}

\begin{abstract}
Electric spring (ES) was originally proposed as a distributed demand-side management technology for making noncritical loads adaptive to the availability of intermittent renewable power generation. The second generation of ES, fed with batteries (ES-2) and associated with a noncritical load, can form a new kind of combined smart load and distributed energy storage technology for smart grids. With its four-quadrant operation, ES-2 is able to offer ancillary grid services in addition to its major functions of voltage and frequency regulation. This paper presents the operating principles and the input current control of ES-2 for power quality improvement such as power factor correction and harmonics reduction. The operating principles and the proposed input current control have been verified with the experimental results obtained from a smallscale power grid. Another weak single-phase power system fed by intermittent wind power is set up to prove the combined operation of ES-2 for power quality improvement and ES-1 (ES with capacitor storage) for voltage stabilization. The experimental results show that ES-2 with input current control can carry out power quality improvement as its ancillary function.
\end{abstract}

Index Terms-Electric Springs (ESs), input current control, power quality, smart grids, smart loads.
At present, various methods for demand-side management have been proposed. They can be classified into time-based strategies and incentive-based strategies [7]. In general, the demand-side technologies require the participation of end users in making the decision of whether to respond to requests broadcasted by grid operators [8]. One obvious drawback is that the demand response with human-in-loop cannot enact automatically and is thus insufficient in resisting unpredictable contingencies [9]. The energy storage system located at the demand side can smooth the demand profile and react fast to transient events, but it remains an expensive solution [10].

Based on power electronics technology, the electric spring (ES) offers a fast solution in addressing power quality issues on the demand side. It possesses a few distinctive features, including the abilities to: 1) conduct direct reactive power compensation in maintaining a stable mains voltage; 2) offer indirect active power control in allowing the demand to follow the availability of renewable generation in a continuous and instantaneous fashion; and 3) operate without critical communication infrastructure. The association of an ES with a noncritical load (such as an electric water heater) essentially turn the load into a smart load that consumes energy adaptively. In typical commercial and residential buildings, about $45 \%$ of loads can be considered as noncritical [11].

The ES-1 presented in [12] uses reactive power of the power inverter and modulates the active power of the noncritical load to stabilize the mains voltage. Its second version (ES-2) proposed in [13] has more diverse functions. By adding battery storage across the dc link, ES-2 possesses eight operating modes and can provide both active and reactive power compensations. ES-2 with its associated battery storage also forms a new kind of combined smart loads and distributed energy storage technology. Based on ES-2, the three-phase ES was first introduced in [14]. It was implemented to reduce the power imbalance in a three-phase four-wire power system and also retains the useful function of ES-1 for voltage stabilization. Since the first paper in ES appeared in 2012 [12], active research on this topic has been conducted in the U.K. [15]-[17], Denmark [18], [19], China [20], Singapore [21], [22], Middle East [23], [24], and India [25], [26].

The original uses of distributed ES focus primarily on the instantaneous balance of power supply and demand with the aims of mitigating voltage and frequency fluctuations caused by the injection of intermittent renewable energy into the power grid. This project explores new application potential of ES-2 in improving the power quality of the distribution (lowvoltage) power grids, whilst retaining their original functions.

Unlike traditional flexible AC transmission (FACT) devices that are installed in a centralized manner for improving

Digital Object Identifier 10.1109/JESTPE.2016.2637398 


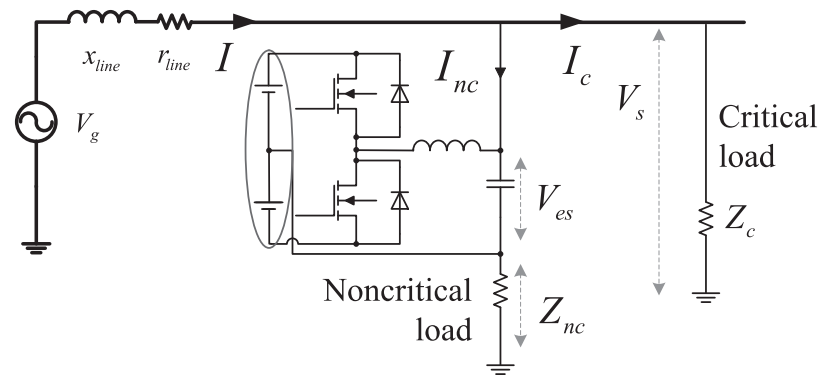

Fig. 1. Practical setup of ES-2.

power quality and controlling power flow in high-voltage and medium voltage transmission networks [27]-[30], ES is a distributed technology installed in the low-voltage distribution networks. The ES deals with the power quality issues on the demand side in a highly disturbed manner. Numerous ESs are expected to be distributed over the power grid in order to support system stability and provide power compensation (i.e., an analogy of using an array of mechanical springs to support a mattress). Thus, ES-2 can be perceived as a decentralized type of series power compensator that can voluntarily adapt the power of noncritical load in maintaining the supply-to-demand balance and possesses the power factor correction (PFC) features. This paper is an extension of a conference paper [31] and includes the full analysis and additional experimental results. These new results confirm that the integration of ESs and adaptive loads can perform PFC at both stable power grids and weak power grids.

\section{PRINCIPLES OF THE ES FOR PFC}

\section{A. Operating Modes of ES-2}

ES-2 is formed by adding a battery across the dc link of the original version (Fig. 1). Compared with ES-1 with capacitors, ES-2 can generate a voltage with any arbitrary phase angle, thereby allowing both active and reactive power to be exchanged. Compared with ES-1, ES-2 can provide six more operating modes in addition to inductive and capacitive mode.

The typical setup of the ES in a simple distribution grid is shown in Fig. 1. The operating mode of ES-2 is determined by the phasor relationship of $\boldsymbol{V}_{\mathrm{es}}$ and $\boldsymbol{I}_{\mathrm{nc}}$. For ES-1 with capacitors, $\boldsymbol{V}_{\mathrm{es}}$ can only be perpendicular to $\boldsymbol{I}_{\mathrm{nc}}$. However, for ES-2, $\boldsymbol{V}_{\mathrm{es}}$ can be in or out of phase with $\boldsymbol{I}_{\mathbf{n}}$ to give two more primary operating modes: 1) negative-resistive mode when an ES generates active power by discharging the batteries; and 2) resistive mode when an ES active power by charging the batteries. Thus, ES-2 possesses four primary operating modes. Building upon this, four other secondary operating modes, which are combinations of the four primary operating modes, are possible additions.

To simplify the discussion, the following assumptions are made. In the distribution power system given in Fig. 1, the mains voltage $\left(\boldsymbol{V}_{S}\right)$ is considered to be constant, and the noncritical load $\left(\boldsymbol{Z}_{\mathrm{nc}}\right)$ is resistive type. The operating mode of ES-2 can thus be determined by observing the vector positions of ES voltage $\left(\boldsymbol{V}_{\mathrm{es}}\right)$ and noncritical load voltage $\left(\boldsymbol{V}_{\mathbf{n c}}\right)$. From

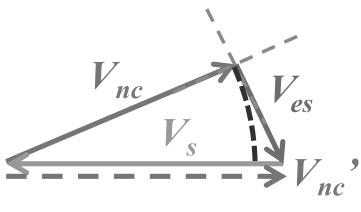

(a)

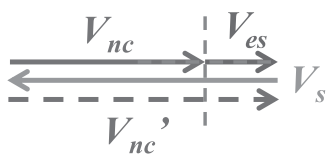

(c)

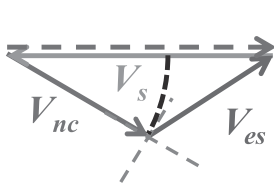

(e)

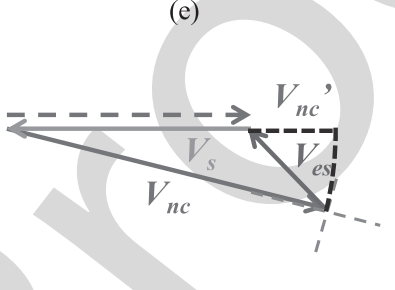

(g)

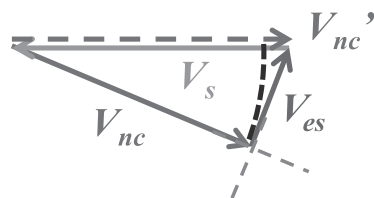

(b)

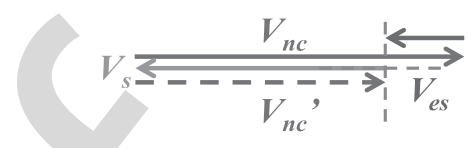

(d)

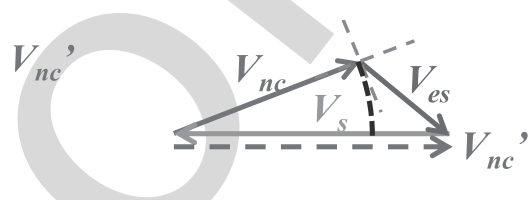

(f)

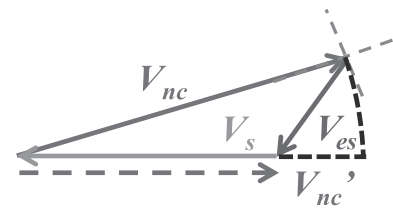

(h)
Fig. 2. Voltage vectors of the eight operating modes of ES-2. (a) Capacitive mode. (b) Inductive mode. (c) Resistive mode. (d) Negative resistive mode (e) Inductive plus resistive mode. (f) Capacitive plus resistive mode. (g) Inductive plus negative resistive mode. (h) Capacitive plus negative resistive mode.

Fig. 2(a) and (b), pure capacitive and inductive modes can be accomplished by setting $\boldsymbol{V}_{\text {es }}$ to be perpendicular to $\boldsymbol{V}_{\text {nc }}\left(\boldsymbol{V}_{\text {es }}\right.$ is $90^{\circ}$ leading $\boldsymbol{V}_{\mathbf{n c}}$ for inductive mode and $90^{\circ}$ lagging $\boldsymbol{V}_{\mathbf{n c}}$ for capacitive mode). For these operating modes, ES-2 only exchanges reactive power with the power source. The original noncritical load voltage $\left(\boldsymbol{V}_{\mathbf{n c}}^{\prime}\right.$, the blue-dotted vector when ES-2 is absent), which is in opposite direction to the mains voltage $\left(\boldsymbol{V}_{s}\right)$, is relocated to a new position $\boldsymbol{V}_{\mathbf{n c}}$ (solid blue line) after the introduction of $\boldsymbol{V}_{\text {es }}$. As a result, $\boldsymbol{V}_{s}$ is decomposed into $\boldsymbol{V}_{\text {es }}$ and $\boldsymbol{V}_{\mathrm{nc}}$, which reduces the active power of noncritical loads. Thus, ES-2 in the inductive mode can reduce active power and increase reactive power, while ES-2 in the capacitive mode can reduce both active and reactive power. Fig. 2(c) and (d) show the voltage vectors of ES-2 working in resistive and negative-resistive modes. In both the cases, only active power is exchanged between ES-2 and the power source. The ES-2 in resistive mode introduces $\boldsymbol{V}_{\mathrm{es}}$, which suppresses $\boldsymbol{V}_{\mathbf{n c}}^{\prime}$ to $\boldsymbol{V}_{\mathbf{n c}}$ and thus reduces the active power of noncritical loads. In contrast, $\boldsymbol{V}_{\text {es }}$ of negative-resistive mode increases $\boldsymbol{V}_{\mathbf{n c}}^{\prime}$ to $\boldsymbol{V}_{\mathbf{n c}}$ and thus boosts the active power of noncritical loads.

Based on these four primary operating modes, four hybrid secondary operating modes would be possible, as shown in Fig. 2(e)-(h), in which active and reactive power are simultaneously exchanged between ES-2 and the power source. 


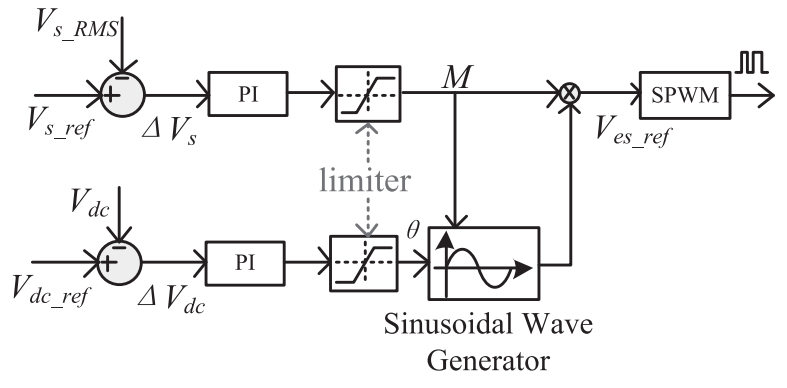

Fig. 3. Input voltage control of ES-1 [12].

Specifically, the four secondary modes are, namely, the resistive plus inductive mode, resistive plus capacitive mode, negative-resistive plus inductive mode, and negative-resistive plus capacitive mode. In all the eight operating modes, the introduction of the $\boldsymbol{V}_{\mathrm{es}}$ can change the loading of the system and thus change the state of the line current.

\section{B. Principle of ES-2 for PFC}

One particular application of ES-2 and its eight operating modes is PFC, which is used to minimize reactive power exchange by controlling the loading current to be in phase with the mains voltage. This technique is common in high-voltage transmissions with centralized compensation. In future smart grids, ES-2 can be installed in low-voltage distribution grid to perform the same task on the demand side.

The hardware implementation of ES-2 for PFC is shown in Fig. 1. The ES-2 here provides one regulated mains on its input and the other adaptive mains on its output. The noncritical load using the adaptive mains can help the utility companies to stabilize the power system and enhance the power quality. In the original ES implementation [12], the "input voltage control" is implemented to address the voltage fluctuation caused by intermittent renewable energy. The simplified control diagram is given in Fig. 3. Different from the ES-1 for voltage regulation, ES-2 is implemented with the "input current control" here to reduce the reactive power of the load bank.

In the setup shown in Fig. 1, the line current $(\boldsymbol{I})$ can be expressed as

$$
I=\frac{V_{s}-V_{\mathrm{es}}}{Z_{\mathrm{nc}}}+\frac{V_{s}}{Z_{c}}
$$

where $\boldsymbol{I}$ is the line current, $\boldsymbol{V}_{S}$ is the mains voltage, $\boldsymbol{V}_{\mathrm{es}}$ is the output voltage of ES-2, $\boldsymbol{Z}_{\mathrm{nc}}$ is the impedance of the noncritical load, and $\boldsymbol{Z}_{c}$ is the impedance of the critical load.

To further understand the relationship of $\boldsymbol{I}$ and $\boldsymbol{V}_{\mathrm{es}}$, the distribution line impedance $\left(\boldsymbol{Z}_{\text {line }}\right)$ is taken into account, which leads to

$V_{s}=\frac{V_{g}+\frac{Z_{\text {line }}}{Z_{\mathrm{nc}}} V_{\mathrm{es}}}{1+\frac{Z_{\text {line }}}{Z_{c}}+\frac{Z_{\text {line }}}{Z_{\mathrm{nc}}}}$

$192 \quad I=\frac{\frac{1}{Z_{c}}+\frac{1}{Z_{\mathrm{nc}}}}{1+\frac{Z_{\text {line }}}{Z_{c}}+\frac{Z_{\text {line }}}{Z_{\mathrm{nc}}}} V_{g}+\left(\frac{\left(\frac{1}{Z_{c}}+\frac{1}{Z_{\mathrm{nc}}}\right) \frac{Z_{\mathrm{line}}}{Z_{\mathrm{nc}}}}{1+\frac{Z_{\mathrm{line}}}{Z_{c}}+\frac{Z_{\mathrm{line}}}{Z_{\mathrm{nc}}}}-\frac{1}{Z_{\mathrm{nc}}}\right) V_{\mathrm{es}}$.
Equation (3) shows that in a power system with given $\boldsymbol{Z}_{\mathrm{nc}}$, $\boldsymbol{Z}_{c}$, and $\boldsymbol{Z}_{\text {line }}$, and a stable mains voltage $\boldsymbol{V}_{g}$ (or in a weak power grid with unstable mains voltage, the ES is implemented to maintain a stable mains voltage), the ES voltage $\boldsymbol{V}_{\text {es }}$ can be modulated to compensate for the line current $\boldsymbol{I}$.

To assist the control design, further mathematic analysis is conducted here. In a power system with fixed operating frequency (i.e., $f_{s}=50 \mathrm{~Hz}$ ), all the parameters in fundamental frequency can be expressed in the form of vectors and be located in one synchronous frame. When $\boldsymbol{V}_{g}$ is chosen as the reference vector $\left(\boldsymbol{V}_{g}=\left|V_{g}\right| \angle 0^{\circ}\right)$, these vectors can have constant amplitude and phase angle. By applying the notations given in (4) and (5), (3) is further transformed into (6) as

$$
\begin{aligned}
& \frac{\frac{1}{Z_{c}}+\frac{1}{Z_{\mathrm{nc}}}}{1+\frac{Z_{\text {line }}}{Z_{c}}+\frac{Z_{\text {line }}}{Z_{\text {nc }}}}=b_{1}+b_{2} j \\
& \left(\frac{\left(\frac{1}{Z_{c}}+\frac{1}{Z_{\mathrm{nc}}}\right) \frac{Z_{\text {line }}}{Z_{\text {nc }}}}{1+\frac{Z_{\text {line }}}{Z_{c}}+\frac{Z_{\text {line }}}{Z_{\text {nc }}}}-\frac{1}{Z_{\text {nc }}}\right)=b_{3}+b_{4} j \\
& \left\{\begin{array}{l}
I_{d \_1 \text { st }}=b_{1} V_{g}+b_{3} V_{\text {esd_1st }}-b_{4} V_{\text {esq_1st }} \\
I_{q_{-} 1 \text { st }}=b_{2} V_{g}+b_{3} V_{\text {esq_1st }}+b_{4} V_{\text {esd_1st }} .
\end{array}\right.
\end{aligned}
$$

Equation (6) indicates that one single set of solution of fundamental active and reactive ES voltage ( $V_{\text {esd_1st }}$ and $\left.V_{\text {esq_1st }}\right)$ can be determined with the given fundamental active and reactive line currents (i.e., the references of fundamental active and reactive line current, $I_{d \_ \text {ref_1st }}$ and $I_{q}$ ref_1st $)$. In the control design, the fundamental active ES voltage $\left(V_{\text {esd_1st }}\right)$ is used to regulate the $d$ component of the fundamental line current $\left(I_{d_{-} 1 \mathrm{st}}\right)$, and the fundamental reactive ES voltage ( $\left.V_{\text {esq_1st }}\right)$ is left to compensate the $q$ component of the fundamental line current $\left(I_{q_{-} 1 \mathrm{st}}\right)$.

\section{Principle of ES-2 for PFC}

The usefulness of ES-2 in compensating the line current can be extended to reduce the harmonics generated by nonlinear load that commonly has a front-end converter for power modulation. Examples of nonlinear loads include power supplies for telecom systems, banking machines, and servers. Obviously, certain nonlinear loads such as banking machine require a stable power supply and thus can be considered as critical loads. The ES and its associated noncritical load can be used to remove the adverse effects caused by nonlinear loads. The principle of using the ES to remove the harmonics in line current can be mathematically expressed by rewriting (1) in sinusoidal form and extending it with the consideration of the harmonics. To simplify the analysis, noncritical load is considered as pure resistive load in (7), as shown at the bottom of the next page, in which $i$ denotes the order of harmonics, $\omega$ denotes the fundamental frequency, $\theta_{I} \theta_{V s} \theta_{\mathrm{Ves} \_i} \theta_{\mathrm{Ic} \_i}$ are, respectively the phase angle of line current, mains voltage, ES voltage, and critical load current.

To mitigate the harmonics, the second part on the righthand side of (7) must be equal to zero, so that $\boldsymbol{I}$ contains only a fundamental component. Thus, this requires ES-2 to generate corresponding voltage harmonics, which are of the same orders as the harmonics in $\boldsymbol{I}_{c}$. The remaining first part 
on the left-hand side of (7) represents the filtered line current at the fundamental frequency.

\section{Load-Dependent Characteristics}

The above assumption of noncritical load as pure resistive load is not a necessary condition in implementing an ES system [15]-[17]. Here, (1) is rewritten as (8) to evaluate the impact of noncritical loads on the operation of the ES

$$
I=\left(\frac{1}{Z_{\mathrm{nc}}}+\frac{1}{Z_{c}}\right) \cdot V_{s}-\frac{1}{Z_{\mathrm{nc}}} \cdot V_{\mathrm{es}}
$$

The second part on the right-hand side of (8) indicates the variable part of noncritical current ( $\Delta \boldsymbol{I}_{\mathrm{nc}}$ ) with respect to the ES voltage. In the synchronous frame established in Section II-B, the second part on the right-hand side of (8) can be rewritten as

$$
\left\{\begin{array}{l}
\Delta I_{\mathrm{nc} \_d}=\frac{1}{\left|Z_{\mathrm{nc}}\right|}\left(-\mathrm{PF} \cdot V_{\mathrm{es} \_d}-\sqrt{1-\mathrm{PF}^{2}} \cdot V_{\mathrm{es} \_q}\right) \\
\Delta I_{\mathrm{nc} \_q}=\frac{1}{\left|Z_{\mathrm{nc}}\right|}\left(\sqrt{1-\mathrm{PF}^{2}} \cdot V_{\mathrm{es} \_d}-\mathrm{PF} \cdot V_{\mathrm{es} \_q}\right)
\end{array}\right.
$$

if the power factor of the noncritical load is considered.

Equation (9) further gives

$$
\Delta I_{\mathrm{nc} \_d}^{2}+\Delta I_{\mathrm{nc} \_q}^{2}=\frac{V_{\mathrm{es}}^{2}}{\left|Z_{\mathrm{nc}}\right|^{2}}
$$

From (9) and (10), two general conclusions can be drawn on the impact of noncritical load on the operation of the ES system as follows.

1) The power factor of noncritical load has no impact on the dispatchable range of noncritical load current. The amplitudes of ES voltage and load impedance determine the boundary of this dispatchable range.

2) The power factor of the noncritical load determines the weighting of $V_{\text {es } \_d}$ and $V_{\text {es } \_q}$ on $\Delta I_{\text {nc } \_d}$ and $\Delta I_{\text {nc } \_q}$. For the case of pure resistive load, $\Delta I_{\mathrm{nc} \_} d$ and $\Delta I_{\mathrm{nc} \_q}$ are, respectively, dependent on $V_{\text {es_ } d}$ and $V_{\text {es_ } q}$.

\section{INPUT CURRENT CONTROL OF ES-2 FOR POWER QUALITY IMPROVEMENT}

\section{A. Structure of Input Current Controller}

Based on the above discussion, an input current controller should be used for ES-2 in regulating the line current. The complete input current control consists of two parts, one for reactive power compensation and the other for harmonics cancellation. These two parts can operate independently or collectively.

The first part for reactive power compensation is highlighted with the blue rectangle, as shown in Fig. 4. A fast Fourier transformation (FFT) is set up to derive the frequency

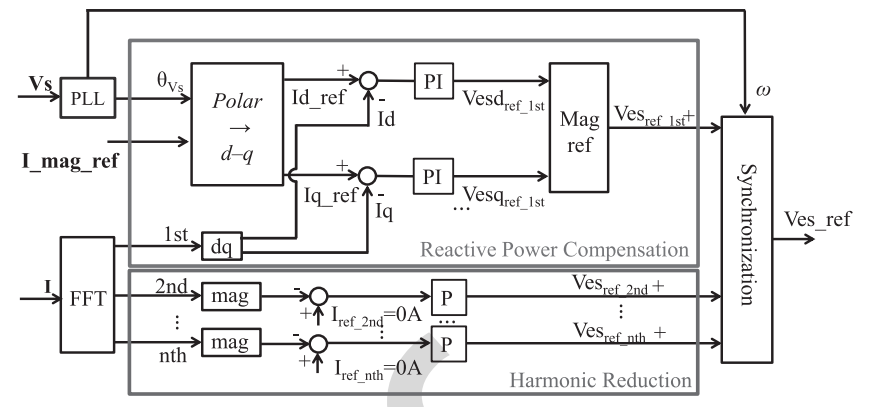

Fig. 4. Control diagram of ES for power quality improvement.

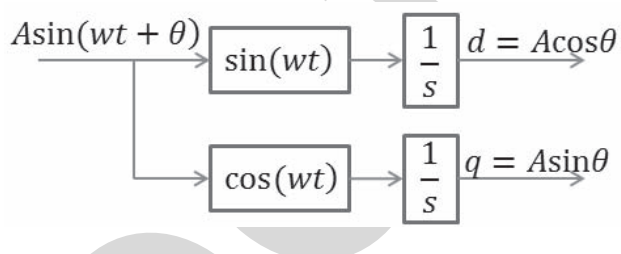

Fig. 5. $d-q$ transformation.

sequences of line current. The fundamental line current is fed back and decomposed into active $\left(I_{d_{-} 1 \mathrm{st}}\right)$ and reactive $\left(I_{q_{-} 1 \mathrm{st}}\right)$ current. Equations (11) and (12) give the mathematical expressions of the "polar to $d-q$ " transformation, and Fig. 5 shows the corresponding block diagram

$$
\begin{aligned}
& d=A \cos \theta=\frac{2}{T} \int_{T_{n}}^{T_{n+1}} A \sin (\omega t+\theta) \sin (\omega t) d t \\
& q=A \sin \theta=\frac{2}{T} \int_{T_{n}}^{T_{n+1}} A \sin (\omega t+\theta) \cos (\omega t) d t .
\end{aligned}
$$

To minimize the reactive power consumption of the load bank, the reference of reactive line current $\left(I_{q_{-} \text {ref_lst }}\right)$ is set to be zero $\left(I_{q_{-} \text {ref_1st }}=0 \mathrm{~A}\right)$. The reference of active line current ( $\left.I_{d_{-} \text {ref_1st }}\right)$ is set to keep the total active power unchanged. $I_{d_{-} 1 \mathrm{st}}$ and $I_{q_{-} 1 \mathrm{st}}$ are compared with their references $\left(I_{d_{-} \text {ref_1 } 1 \mathrm{st}}\right.$ and $\left.I_{q_{-} \text {ref_1st }}\right)$. Two PI controllers are set up to process the error of the respective active and reactive current in generating the fundamental active and reactive ES voltage reference $\left(V_{\text {esd_ref_1st }}\right.$ and $\left.V_{\text {esq_ref_1st }}\right)$. The mathematical expressions of the control are given as

$$
\begin{aligned}
& V_{\text {esd_ref_1st }}=\left(K_{p \_I d}+K_{i_{-} \mathrm{Id}} / s\right) \cdot\left(I_{d \_ \text {ref_1 } 1 \mathrm{st}}-I_{d \_1 \mathrm{st}}\right) \\
& V_{\text {esq_ref_1st }}=\left(K_{p_{-} \mathrm{Iq}}+K_{i_{-} \mathrm{Iq}} / s\right) \cdot\left(I_{q_{-} \text {ref_1st }}-I_{q_{-} 1 \mathrm{st}}\right) \text {. }
\end{aligned}
$$

The control loops inside the red box in Fig. 4 are the part of the input current control for harmonics mitigation. The harmonic currents in the second and higher orders acquired by the FFT block are sent to the controller. To remove the harmonics contained in line current, the amplitude of all the

$$
\begin{aligned}
\sum_{i=1}^{n} I_{i \mathrm{th}} \sin \left(i \omega t+\theta_{I_{i \mathrm{th}}}\right)= & \left(\frac{V_{s} \sin \left(\omega t+\theta_{V s}\right)-V_{\text {es_1st }} \sin \left(\omega t+\theta_{\text {Ves_1st }}\right)}{R_{\mathrm{nc}}}+I_{C_{-} 1 \mathrm{st}} \sin \left(\omega t+\theta_{\mathrm{Ic} \_1 \mathrm{st}}\right)\right) \\
& +\left(-\frac{1}{R_{\mathrm{nc}}} \sum_{i=2}^{n} V_{\text {es } \_i \mathrm{th}} \sin \left(i \omega t+\theta_{\text {Ves } \_i \mathrm{th}}\right)+\sum_{i=2}^{n} I_{C_{-} i \mathrm{th}} \sin \left(i \omega t+\theta_{\mathrm{Ic} i \mathrm{th}}\right)\right)
\end{aligned}
$$




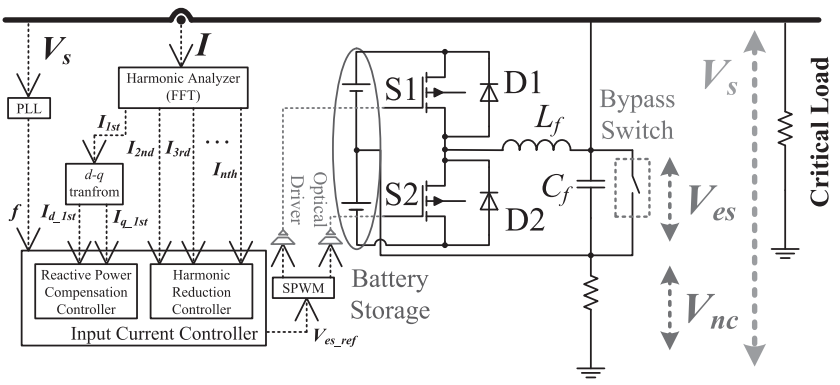

Fig. 6. Hardware implementation of an input current controller.

TABLE I

SPECIFICATIONS OF ES-2 HARDWARE

\begin{tabular}{ccc}
\hline \hline Descriptions & Parameters & Values \\
\hline Switching frequency & $f_{\text {switch }}$ & $20 \mathrm{kHz}$ \\
MOSFET switches & $S_{1}, S_{2}$ & IRFP30N50 \\
Filter inductor & $L_{f}$ & $L=500 \mu \mathrm{H}$ \\
Filter capacitor & $C_{f}$ & $C=13.2 \mu \mathrm{F}$ \\
Battery voltage & $V_{\text {battery }}$ & $2 \times 125 \mathrm{~V}, 5 \mathrm{AH} \mathrm{Lead-Acid}$ \\
Sampling frequency & $f_{s}$ & $10 \mathrm{kHz}$ \\
\hline \hline
\end{tabular}

harmonic current references in the second and higher orders are set to zero $\left(I_{\text {ref_2nd }}=0 \mathrm{~A}, I_{\text {ref_3rd }}=0 \mathrm{~A}, \ldots, I_{\text {ref } \_n \text {th }}=\right.$ 0 A). The phasor information of these harmonic currents is fed back to the synchronization stage. P controllers are implemented to process the errors of the amplitude of the harmonic currents in deriving the ES voltage references in the second and higher orders. The general control for the mitigation of current harmonics is mathematically presented as

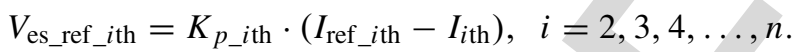

\section{B. Hardware Implementation of Input Current Controller}

A prototype of the ES-2 system with the implementation of the "input current control" is developed. The hardware structure is shown in Fig. 6. The power converter used for ES2 is a half-bridge inverter with batteries on dc link and with an $L C$ output filter. In the hardware setup, a relay is connected across the output capacitor to bypass ES. This arrangement can show the different conditions in the system before and after ES-2 is switched ON. Blocks including feedback processing block, phase lock loop for synchronization, $d-q$ transformation block for decoupling, and sinusoidal pulsewidth modulation for inverter control are also set up. The controller is implemented in dSpace 1104. The sampling frequency is set to be $10 \mathrm{kHz}$. The PWM pulse has a switching frequency of $20 \mathrm{kHz}$ and a deadband of $20 \mathrm{nS}$. The specifications of the hardware setup are given in Table I.

\section{EXPERIMENTAL RESUlts}

\section{A. ES-2 for Reactive Power Compensation in a Stiff Power} System

A low-voltage single-phase power system is set up as shown in Fig. 7. It consists of a constant ac power source, a short

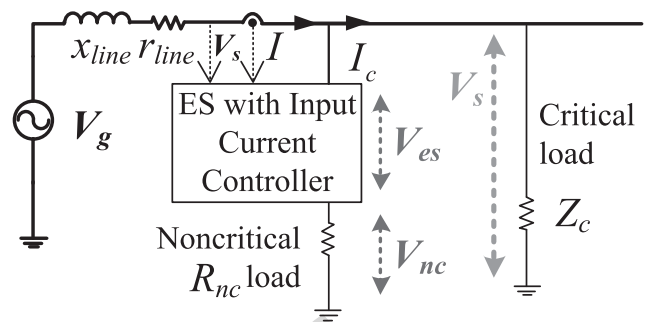

Fig. 7. Experimental setup.

TABLE II

SPECIFICATIONS OF EXPERIMENTAL SETUP

\begin{tabular}{ccc}
\hline \hline Descriptions & Parameters & Values \\
\hline $\begin{array}{c}\text { Power source } \\
\text { voltage }\end{array}$ & $V_{g}$ & $110 \mathrm{~V}(\mathrm{RMS})$ \\
$\begin{array}{c}\text { Distribution line } \\
\text { impedance }\end{array}$ & $Z_{\text {line }}$ & line \\
Noncritical load 1 & $R_{n c 1}$ & $\Omega .2, x_{\text {line }}=0.8 \Omega$ \\
Noncritical load 2 & $R_{n c 2}$ & $120 \Omega$ \\
Critical load 1 & $Z_{c l}$ & $150 \Omega$ \\
Critical load 2 & $Z_{c 2}$ & $220+j 220 \Omega$ \\
& (capacitive-resistive type) & $220-j 220 \Omega$ \\
\end{tabular}

distribution line, a resistive noncritical load, an ES-2, and a critical load. Specifications of the setup can be found in Table II. The ES-2 is programmed to perform reactive power compensation with the input current control. A capacitiveresistive and an inductive-resistive critical load with low PF are used, respectively, to examine the reactive power compensation capability of ES-2. In the middle of operations, the noncritical load is changed from 120 to $150 \Omega$ for evaluating the dynamic response of the ES system.

Measured waveforms of the operating states of the system with a capacitive-resistive critical load are recorded in Fig. 8(a). The enlarged waveforms of the two transient states when ES-2 is turned ON and the noncritical load is changed from 120 to $150 \Omega$ are also included. It can be observed that the ES can react fast enough to the change in noncritical load. Measured waveforms of the first steady states of the system when ES-2 is inactivated are shown in Fig. 8(b). The system has a PF of 0.94 (leading). Measurements of the second steady states of the system are shown in Fig. 8(c). ES-2 operates in inductive mode to compensate the phase angle of line current $(\boldsymbol{I})$ to $1^{\circ}$, and the PF of the system is corrected to 0.99 (leading). Measurements of the third steady states are recorded in Fig. 8(d) to show the operation of the ES system after the noncritical load is changed to $150 \Omega$. The PF remains compensated to 0.99 (leading), when ES-2 operates in inductive mode and generates a compensation voltage with a larger RMS value to match the new load condition.

The second experiment is conducted with an inductiveresistive critical load. ES-2 is turned ON to correct PF to be close to 1.0. Fig. 9(a) shows the measured waveforms of operating states of the ES-2 system and the enlarged waveforms of two transient states when ES-2 is turned ON and the noncritical load is changed from 120 to $150 \Omega$. In the first 
With ES

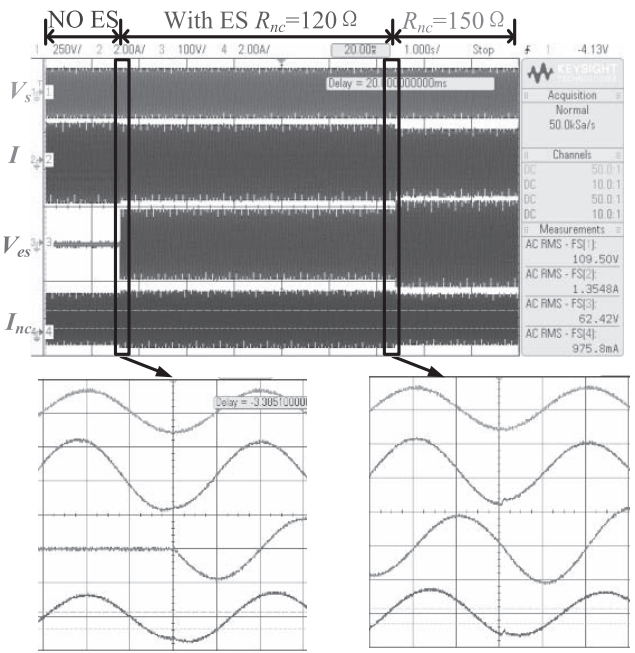

(a)

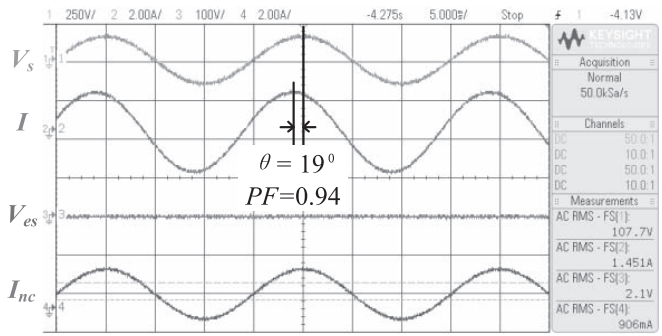

(b)

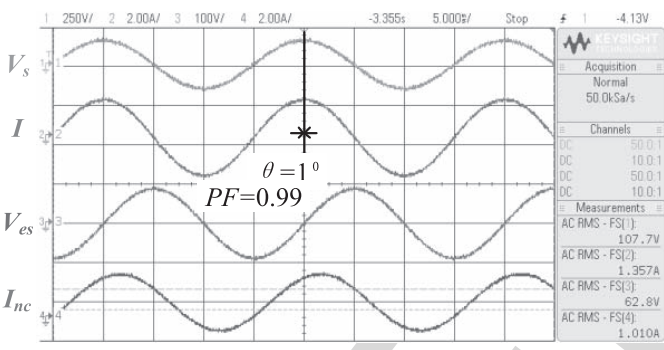

(c)

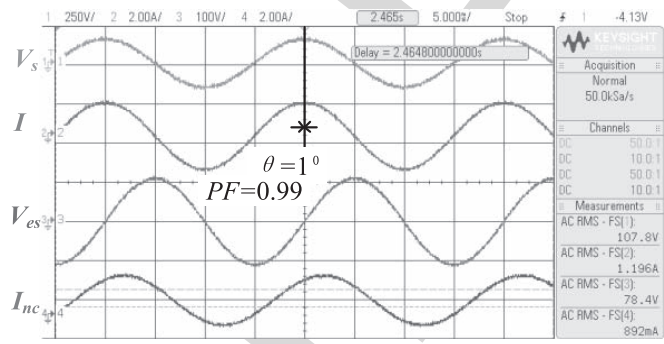

(d)

Fig. 8. (a) Captured waveforms of operating states and enlarged transient states for capacitive-resistive load. (b) Captured waveforms of the steady states without ES-2. (c) Captured waveforms of the steady states with ES-2 $\left(R_{\mathrm{ncl}}=120 \Omega\right)$. (d) Captured waveforms of the steady states with ES-2 $\left(R_{\mathrm{nc} 2}=150 \Omega\right)$. steady states shown in Fig. 9(a), the system is uncompensated and has PF of 0.94 (lagging). In the second steady states shown in Fig. 9(b), ES-2 operates in capacitive mode to correct the PF of the system to 0.99 (lagging). Measurements of the third steady states of the system after the noncritical load are

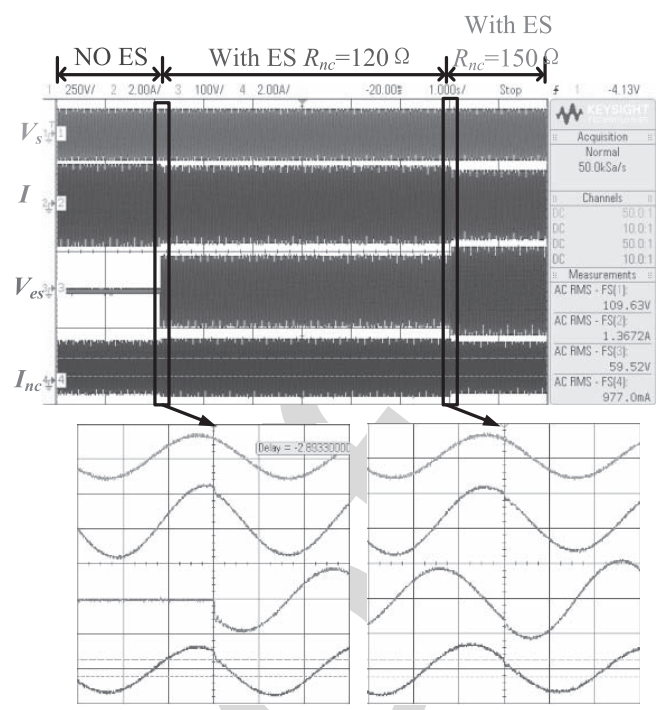

(a)

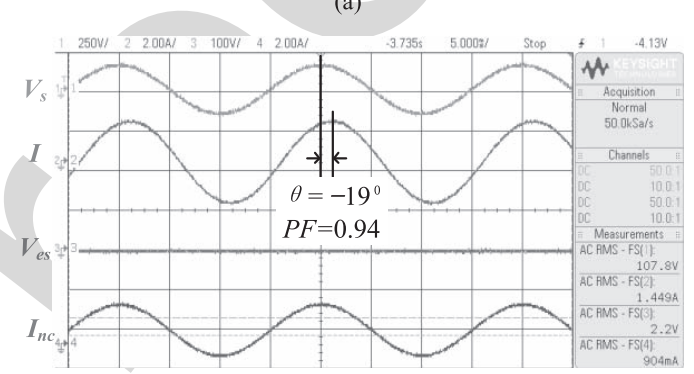

(b)

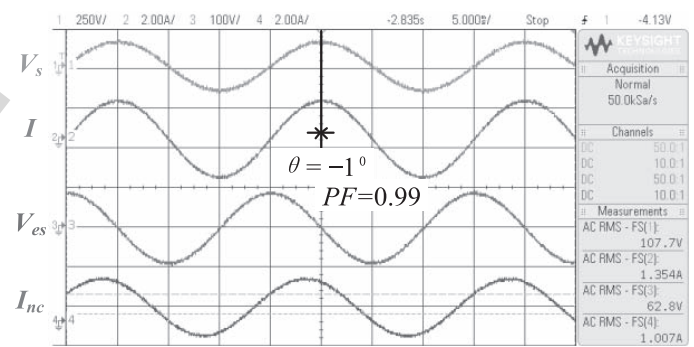

(c)

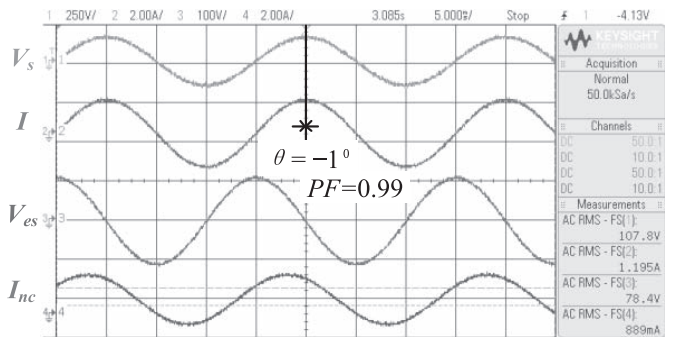

(d)

Fig. 9. (a) Captured waveforms of operating states and enlarged transient states for inductive-resistive load. (b) Captured waveforms of the steady states without ES-2. (c) Captured waveforms of the steady states with ES-2 $\left(R_{\mathrm{nc} 1}=120 \Omega\right)$. (d) Captured waveforms of the steady states with ES-2 $\left(R_{\mathrm{nc} 2}=150 \Omega\right)$.

changed to $150 \Omega$ are shown in Fig. 9(c). The PF of the system remains at 0.99 (lagging), when ES-2 operates in capacitive mode and generates a compensation voltage with a larger RMS value to match the new noncritical load condition. 


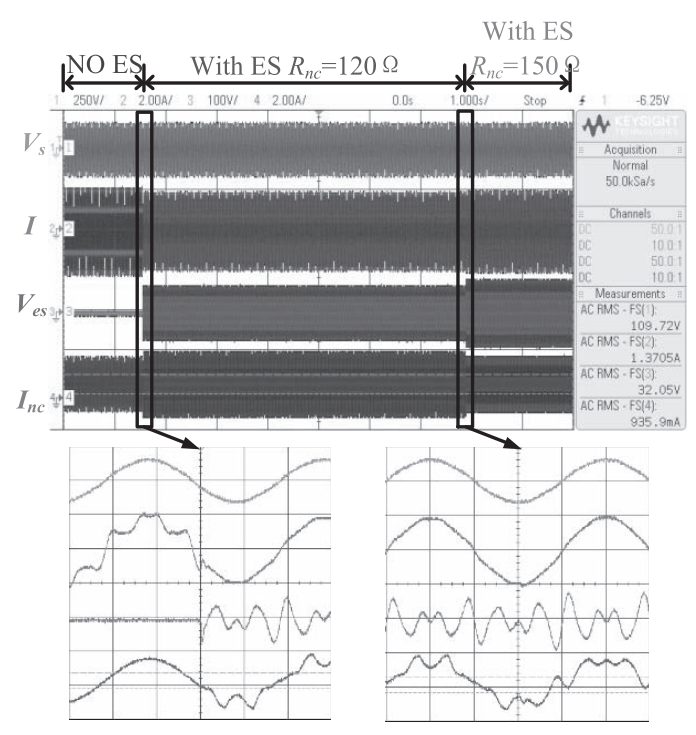

(a)

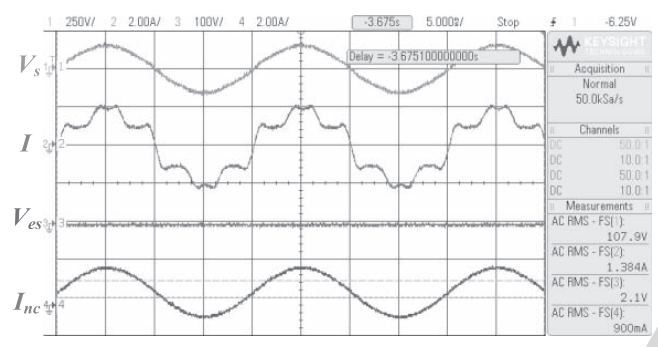

(b)

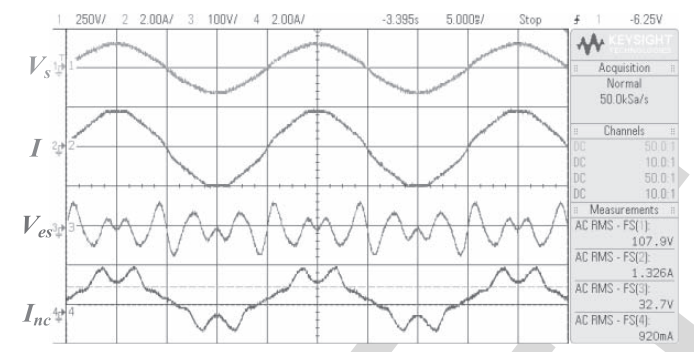

(c)

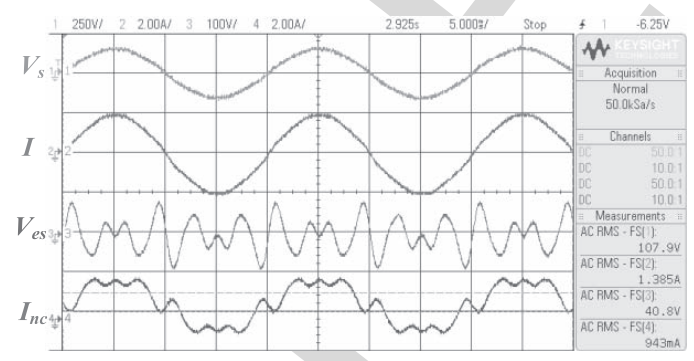

(d)

Fig. 10. (a) Captured waveforms of operating states and enlarged transient states for nonlinear load. (b) Captured waveforms of the steady states without ES-2. (c) Captured waveforms of the steady states with ES-2 $\left(R_{\mathrm{nc} 1}=120 \Omega\right)$. (d) Captured waveforms of the steady states with ES-2 $\left(R_{\mathrm{nc} 2}=150 \Omega\right)$.
TABLE III

SPECIFICATIONS OF POWER System With Two ESs

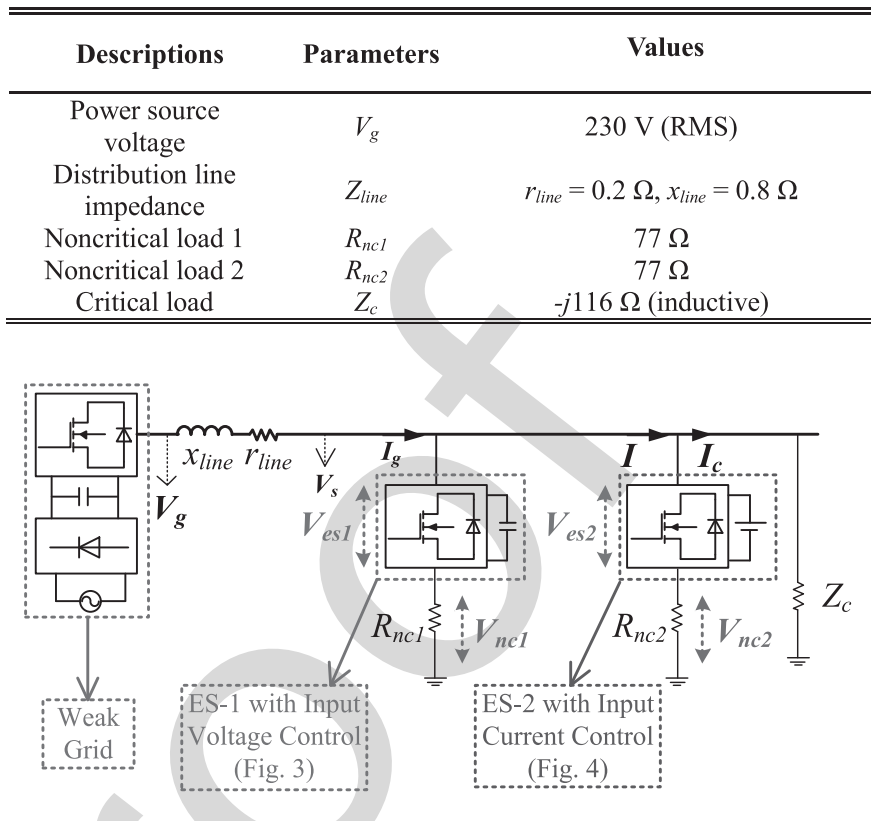

Fig. 11. Experimental setup.

120 to $150 \Omega$ to test the dynamic response of the ES-2 system. Measurements of the operating states of the system are shown in Fig. 10(a). The waveforms of the two transient states when the ES is activated and the noncritical load is changed are enlarged. It can be observed that the ES system reacts fast enough to cope with the sudden change in load condition. Fig. 10(b) shows the measurements of the first steady states of the system before ES-2 is turned ON. The line current $(\boldsymbol{I})$ is severely distorted due to the implementation of the nonlinear load. Measured waveforms of the second steady states of the system when the ES is activated are shown in Fig. 10(c). ES-2 generates the counteracting harmonic voltage to compensate the nonlinear load. The waveform of the line current $(\boldsymbol{I})$ is significantly improved. Measurements of the third steady states after the noncritical load is changed are shown in Fig. 10(d). The ES-2 generates a harmonic voltage with a larger RMS value to match the changed noncritical load condition.

\section{Combined Operation of ES-1 and ES-2}

In this experiment, a weak grid with unstable mains voltage is emulated with a programmable power source. A large critical inductive load is used to simulate a power grid with a low power factor. Two ESs (ES-1 and ES-2) associated with their respective noncritical loads are set up as shown in Fig. 11. Both noncritical loads are assumed to be of resistive type. ES-1 is used to reduce the mains voltage fluctuation. The control algorithm shown in Fig. 3 is adopted here [12]. ES-2 implemented with the input current control is used to improve the power factor. The specifications of the system are given in Table III.

The experimental results in Fig. 12 repeat the useful function of ES-1 to stabilize the mains voltage. Fig. 13 shows the power of critical load. It can be seen that the fluctuation of 


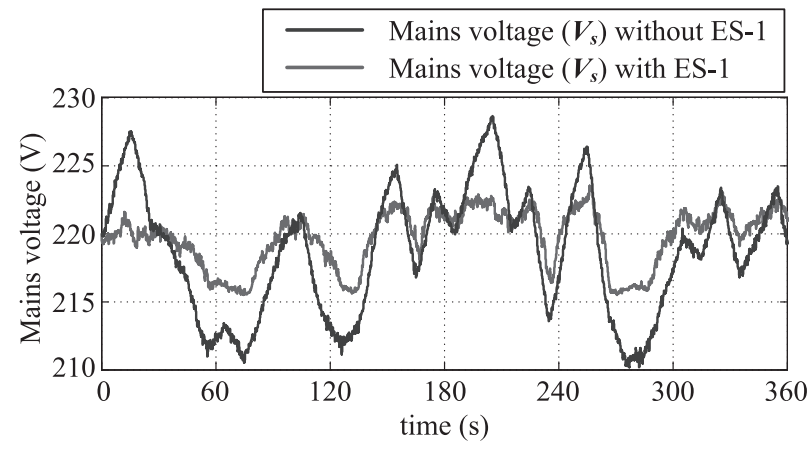

Fig. 12. Mains voltage with and without ES-1 for voltage stabilization.

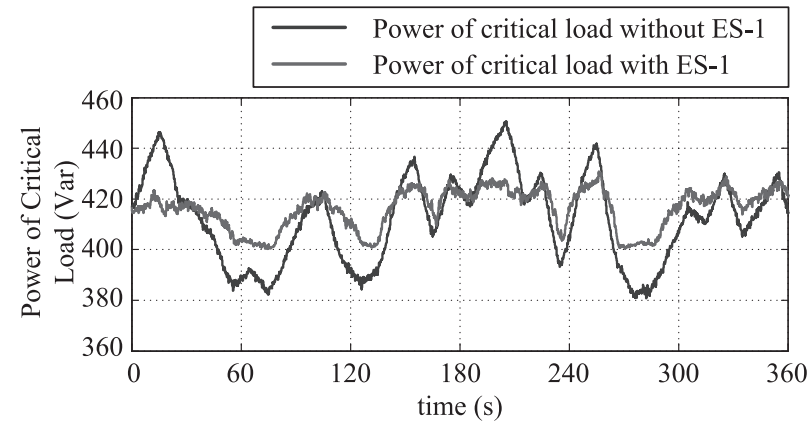

Fig. 13. Power consumption of critical load with and without ES-1.

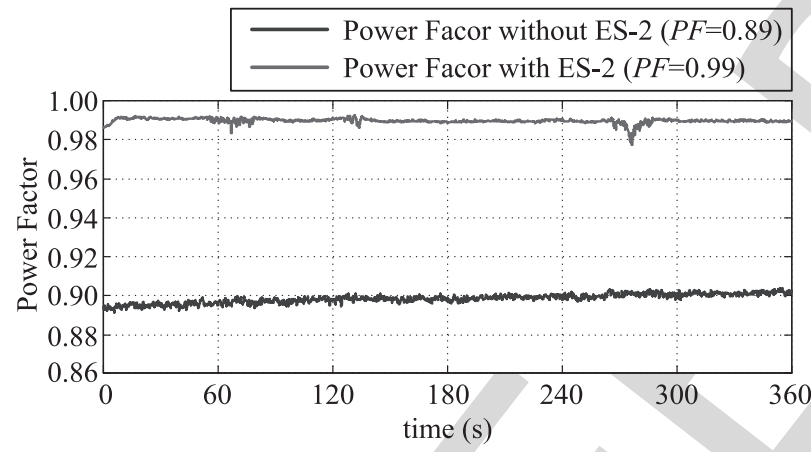

Fig. 14. Power factor with and without ES-2.

presented and practically verified. The joint operation of ES-1 in stabilizing the mains voltage and ES-2 in performing PFC has been experimentally confirmed in a single-phase hardware power system setup. The experimental results indicate the promising performance of the ES technology as a future distributed demand-side management and distributed energy storage solution.

\section{REFERENCES}

[1] H. Farhangi, "The path of the smart grid," IEEE Power Energy Mag., vol. 8, no. 1, pp. 18-28, Jan./Feb. 2010.

[2] V. C. Gungor et al., "Smart grid technologies: Communication technologies and standards," IEEE Trans. Ind. Informat., vol. 7, no. 4, pp. 529-539, Nov. 2011.

[3] A. Vargas and M. E. Samper, "Real-time monitoring and economic dispatch of smart distribution grids: High performance algorithms for DMS applications," IEEE Trans. Smart Grid, vol. 3, no. 2, pp. 866-877, Jun. 2012.

[4] F. Li et al., "Smart transmission grid: Vision and framework," IEEE Trans. Smart Grid, vol. 1, no. 2, pp. 168-177, Sep. 2010.

[5] D. E. Bakken, A. Bose, C. H. Hauser, D. E. Whitehead, and G. C. Zweigle, "Smart generation and transmission with coherent, realtime data," Proc. IEEE, vol. 99, no. 6, pp. 928-951, Jun. 2011.

[6] P. Palensky and D. Dietrich, "Demand side management: Demand response, intelligent energy systems, and smart loads," IEEE Trans. Ind. Informat., vol. 7, no. 3, pp. 381-388, Aug. 2011.

[7] Federal Energy Regulatory Commission (FERC). (Dec. 2012). Assessment of Demand Response and Advanced Metering. [Online]. Available: http://www.ferc.gov/legal/staff-reports/12-20-12-demand-response.pdf

[8] J. S. Vardakas, N. Zorba, and C. V. Verikoukis, "A survey on demand response programs in smart grids: Pricing methods and optimization algorithms," IEEE Commun. Surveys Tut., vol. 17, no. 1, pp. 152-178, 1st Quart., 2015.

[9] T. Samad, E. Koch, and P. Stluka, "Automated demand response for smart buildings and microgrids: The state of the practice and research challenges," Proc. IEEE, vol. 104, no. 4, pp. 726-744, Apr. 2016.

[10] P. F. Ribeiro, B. K. Johnson, M. L. Crow, A. Arsoy, and Y. Liu, "Energy storage systems for advanced power applications," Proc. IEEE, vol. 89 no. 12, pp. 1744-1756, Dec. 2001

[11] Hong Kong Energy End-Use Data 2013, Electrical \& Mechanical Services Department, Hong Kong Government, 2013.

[12] S. Y. R. Hui, C. K. Lee, and F. F. Wu, "Electric springs-A new smart grid technology," IEEE Trans. Smart Grid, vol. 3, no. 3, pp. 1552-1561, Sep. 2012.

[13] S.-C. Tan, C. K. Lee, and S. Y. Hui, "General steady-state analysis and control principle of electric springs with active and reactive power compensations," IEEE Trans. Power Electron., vol. 28, no. 8, pp. 3958-3969, Aug. 2013

[14] S. Yan, S.-C. Tan, C.-K. Lee, B. Chaudhuri, and S. Y. Hui, "Electric springs for reducing power imbalance in three-phase power systems," IEEE Trans. Power Electron., vol. 30, no. 7, pp. 3601-3609, Jul. 2015.

[15] Z. Akhtar, B. Chaudhuri, and S. Y. Hui, "Primary frequency control contribution from smart loads using reactive compensation," IEEE Trans. Smart Grid, vol. 6, no. 5, pp. 2356-2365, Sep. 2015.

[16] Z. Akhtar, B. Chaudhuri, and S. Y. Hui, "Smart loads for voltage control in distribution networks," IEEE Trans. Smart Grid, (early access).

[17] D. Chakravorty, B. Chaudhuri, and S. Y. Hui, "Rapid frequency response from smart loads in great britain power system," IEEE Trans. Smart Grid, (early access)

[18] Q. Wang, M. Cheng, Z. Chen, and Z. Wang, "Steady-state analysis of electric springs with a novel $\delta$ control," IEEE Trans. Power Electron., vol. 30, no. 12, pp. 7159-7169, Dec. 2015.

[19] Q. Wang, M. Cheng, Z. Chen, and G. Buja, "A novel topology and its control of single-phase electric springs," in Proc. Int. Conf. Renew. Energy Res. Appl. (ICRERA), Nov. 2015, pp. 267-272.

[20] X. Che, T. Wei, Q. Huo, and D. Jia, "A general comparative analysis of static synchronous compensator and electric spring," in Proc. IEEE Conf. Expo Transp. Electrific. Asia-Pacific (ITEC Asia-Pacific), Aug./Sep. 2014, pp. 1-5.

[21] K. R. Krishnanand, S. M. F. Hasani, J. Soni, and S. K. Panda, "Neutral current mitigation using controlled electric springs connected to microgrids within built environment," in Proc. IEEE Energy Convers. Congr. Expo. (ECCE), Sep. 2014, pp. 2947-2951. 

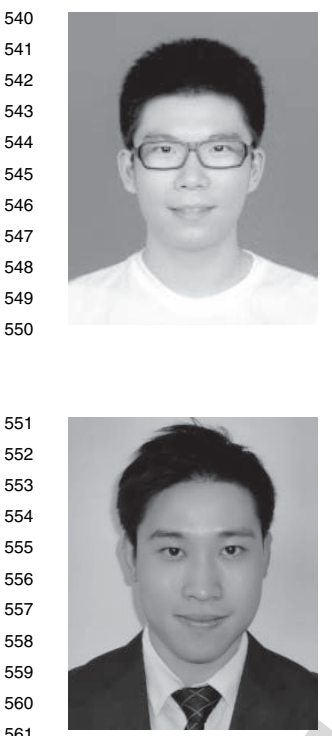

Shuo Yan (M'16) received the B.Eng. degree from the University of South China, Hengyang, China, in 2007, the M.Phil. degree from Southeast University, Nanjing, China, in 2010, and the Ph.D. degree from The University of Hong Kong, Hong Kong, in 2016. $\mathrm{He}$ is currently a Post-Doctoral Research Fellow with the Department of Electrical and Electronic Engineering, The University of Hong Kong. His current research interests include power electronic technology in smart grid, the advance control of renewable energy sources, and microgrid.

Siew-Chong Tan (M'06-SM'11) received the B.Eng. (Hons.) and M.Eng. degrees in electrical and computer engineering from the National University of Singapore, Singapore, in 2000 and 2002, respectively, and the Ph.D. degree in electronic and information engineering from The Hong Kong Polytechnic University, Hong Kong, in 2005.

From 2005 to 2012, he was a Research Associate, Post-Doctoral Fellow, Lecturer, and an Assistant Professor with the Department of Electronic and Information Engineering, The Hong Kong Polytechnic University. In 2009, he was a Visiting Scholar at the Grainger Center for Electric Machinery and Electromechanics, University of Illinois at UrbanaChampaign, Champaign, IL, USA. In 2011, he was a Senior Scientist with the Agency for Science, Technology and Research (A*Star), Singapore, and an Invited Academic Visitor of the Huazhong University of Science and Technology, Wuhan, China. He is currently an Associate Professor with the Department of Electrical and Electronic Engineering, The University of Hong Kong, Hong Kong. He has co-authored the book Sliding Mode Control of Switching Power Converters: Techniques and Implementation (Boca Raton, FL, USA: CRC, 2011). His current research interests include power electronics and control, LED lightings, smart grids, and clean energy technologies.

Dr. Tan serves extensively as a reviewer for various IEEE/IET transactions and journals on power, electronics, circuits, and control engineering. He is an Associate Editor of the IEEE TRANSACTIONS ON POWER ELECTRONICS.

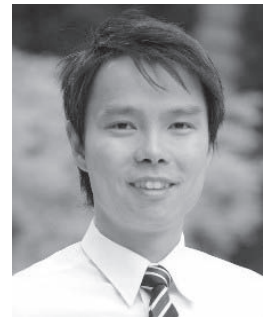

Chi-Kwan Lee (M'08-SM'14) received the B.Eng. and $\mathrm{Ph} . \mathrm{D}$. degrees in electronic engineering from the City University of Hong Kong, Hong Kong, in 1999 and 2004, respectively.

He was a Post-Doctoral Research Fellow with the Power and Energy Research Center, National University of Ireland, Galway, Ireland, from 2004 to 2005. In 2006, he joined the Center of Power Electronics, City University of Hong Kong, as a Research Fellow. He has been a Visiting Researcher with Imperial College London, London, U.K., since 2010. He was a Lecturer of Electrical Engineering with The Hong Kong Polytechnic University, Hong Kong, from 2008 to 2011. He is currently an Assistant Professor with the Department of Electrical and Electronic Engineering, The University of Hong Kong, Hong Kong. His current research interests include wireless power transfer, clean energy technologies, and smart grids.

Dr. Lee received the IEEE Power Electronics Transactions First Prize Pape Award for his publications on Mid-Range Wireless Power Transfer in 2015. $\mathrm{He}$ is a Co-Inventor of the Electric Springs and planar EMI filter.

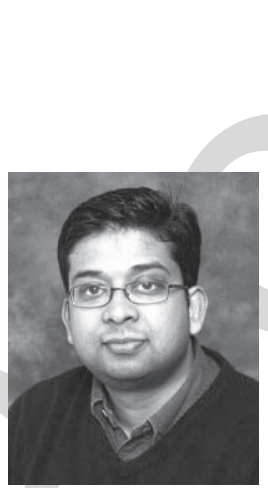

Balarko Chaudhuri (M'06-SM'11) received the $\mathrm{Ph} . \mathrm{D}$. degree in electrical and electronic engineering from Imperial College London, London, U.K., in 2005

$\mathrm{He}$ is currently a Senior Lecturer with the Control and Power Research Group, Imperial College London. His current research interests include power systems stability, grid integration of renewables, HVDC, FACTS, demand response, and smart grids.

Dr. Chaudhuri is a fellow of the Institution of Engineering and Technology and a member of the International Council on Large Electric Systems. He is an Editor of the IEEE TRANSACTIONS ON SMART GRID and an Associate Editor of the IEEE Systems Journal and Elsevier Control Engineering Practice.

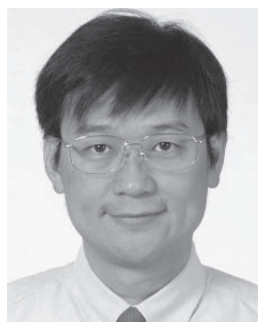

S. Y. Ron Hui (M'87-SM'94-F'03) received the B.Sc. degree (Eng.) (Hons.) from the University of Birmingham, Birmingham, U.K., in 1984, and the D.I.C. and Ph.D. degrees from Imperial College London, London, U.K. in 1987.

He currently holds the Philip Wong Wilson Wong Chair Professorship at The University of Hong Kong, Hong Kong, and a part-time Chair Professorship at Imperial College London. He has authored over 300 technical papers, including more than 220 refereed journal publications, and over 60 of his patents have been adopted by industry.

Dr. Hui received the IEEE Rudolf Chope Research and Development Award from the IEEE Industrial Electronics Society and the IET Achievement Medal (The Crompton Medal) in 2010, and the IEEE William E. Newell Power Electronics Award in 2015. He is an Associate Editor of the IEEE TRANS ACTIONS ON POWER ELECTRONICS and the IEEE TRANSACTIONS ON INDUSTRIAL ELECTRONICS, and an Editor of the IEEE JOURNAL OF EMERGING AND Selected Topics in Power Electronics. His inventions on wireless charging platform technology underpin key dimensions of Qi, the world's first wireless power standard, with freedom of positioning and localized charging features for wireless charging of consumer electronics.

Dr. Hui is a Fellow of the Australian Academy of Technology and Engineering and the Royal Academy of Engineering, U.K. 